\title{
Surface Modification and Alloying of Aluminum and Titanium Alloys with Low-Energy, High-Current Electron Beams
}

\author{
V. P. Rotshtein ${ }^{1,2}$ and V. A. Shulov ${ }^{3}$ \\ ${ }^{1}$ Laboratory of Vacuum Electronics, Institute of High Current Electronics, 2/3, Academichesky Avenue, Tomsk 634055, Russia \\ ${ }^{2}$ Department of Applied Mechanics, Tomsk State Pedagogical University, 60, Kievskaya Street, Tomsk 634061, Russia \\ ${ }^{3}$ Department "Technologies of Production of Engines for Flying Vehicles", Moscow Aviation Institute, \\ 4, Volokolamskoe Shosse, Moscow 125993, Russia \\ Correspondence should be addressed to V. P. Rotshtein, rvp@lve.hcei.tsc.ru
}

Received 17 February 2011; Accepted 6 April 2011

Academic Editor: Jianxin Zou

Copyright ( 2011 V. P. Rotshtein and V. A. Shulov. This is an open access article distributed under the Creative Commons Attribution License, which permits unrestricted use, distribution, and reproduction in any medium, provided the original work is properly cited.

\begin{abstract}
The paper reviews the results of investigations of surface modification and alloying of $\mathrm{Al}$, $\mathrm{Ti}$, and its alloys with a low-energy (up to $\sim 40 \mathrm{keV}$ ), high-current (up to $25 \mathrm{~J} / \mathrm{cm}^{2}$ ) electron beams of microsecond duration under systematically varied conditions. The microstructural evolution of the surface layers of Al alloys (Al2024 and Al6061) and Ti-6Al-4V alloy subjected to pulsed melting as well as changes in surface-sensitive properties of these alloys are considered. Phase formation and properties of Albased and Ti-based surface alloys, synthesized by liquid-phase mixing of multilayer film-substrate systems in wide range of solid solubility, including $[\mathrm{Al} / \mathrm{Si}] / \mathrm{Al},[\mathrm{Al} / \mathrm{C}] / \mathrm{Al},[\mathrm{Zr} / \mathrm{Ti}] / \mathrm{Ti}-6 \mathrm{Al}-4 \mathrm{~V}$, and $\mathrm{Al} / \mathrm{Ti}$, are studied. In case of Ti-based substrates, this method allows to fabricate the single-phase nanocrystalline $\alpha$-(TiZr) surface alloy, free of $\mathrm{Al}$ and $\mathrm{V}$, as well as nanosized and ultrafine grain $\mathrm{TiAl} / \mathrm{Ti}_{3} \mathrm{Al}$-based surface alloys of thickness $\geq 3 \mu \mathrm{m}$ with enhanced mechanical properties.
\end{abstract}

\section{Introduction}

Light aluminum and titanium alloys are very attractive materials for aerospace and automobile industries owing to their low-density and high specific strength. Titanium and its alloys also are widely used for biomedical applications like artificial joints and dental implants. However, such surface-sensitive properties of $\mathrm{Al}$ and $\mathrm{Ti}$ alloys as wear behavior, corrosion resistance, and fatigue strength need to be improved to insure high performance and durability of components.

One of the promising approaches to this goal is the surface treatment of $\mathrm{Al}$ and $\mathrm{Ti}$ alloys with low-energy (up to $\sim 40 \mathrm{keV}$ ), high-current (up to $\sim 50 \mathrm{kA}$ ) electron beams (LEHCEBs) of microsecond duration. The sources of LEHCEBs have developed and built during the last decades by Proskurovsky et al. [1-3] at the Institute of High Current Electronics (Tomsk), especially for surface treatment of materials. At the present time, these sources are superior in performance to other known sources of pulsed electron beams, pulsed lasers, sources of high-power ion beams and pulsed plasma generators used for surface treatment. Important advantages of the LEHCEBs sources are their wide aperture of e-beam $\left(\sim 50 \mathrm{~cm}^{2}\right)$, reliability, high electrical efficiency, and X-ray safety.

The major factors, which determine the microstructure and properties of a material in the e-beam-affected zone are the nonstationary temperature fields induced in the surface layers as result of absorption of a beam energy, and stress fields induced by pulsed heating of the surface. The technique and results of the calculation of temperature and stress fields induced by LEHCEBs are described elsewhere $[2,4,5]$. The promise of LEHCEBs as candidates for surface modification of materials is due to the following circumstances. The electron energy is absorbed within a thin $(\sim 1 \mu \mathrm{m})$ surface layer, and this, in combination with the short-pulse duration, allows one to realize pulsed melting and smoothing of the surface at rather low-energy densities $\left(2-5 \mathrm{~J} / \mathrm{cm}^{2}\right)$. As a result of the heat transfer into underlying layers of the material, the resolidification of the molten layer occurs at a cooling rate of 
$\geq 10^{9} \mathrm{~K} / \mathrm{s}$, which is high enough to form the nonequilibrium microstructures, including amorphous and nanocrystalline ones. One can easily realize a controllable dissolution of second-phase particles as well as evaporation of the nearsurface layers by varying the energy density and the number of pulses, and this, in particular, makes it possible to efficiently clean the surface of carbides, oxides, and other second phases, thus, to improve the corrosion behavior [2, 5-9]. Pulsed melting of film-substrate systems allows one to produce metastable surface alloys with graded structure due to liquid-phase diffusion $[3,5,6,10-15]$. Finally, a propagation of stress wave, caused by pulsed heating, can lead to forming the thick- $(\geq 100 \mu \mathrm{m})$ hardened surface layer $[2,3,6,16]$. The interesting new results of investigation of the surface treatment of steels and alloys with LEHCEBs have been presented in [17-20].

Thus, LEHCEBs' sources offer a unique tool for investigations in materials science and for developing new vacuum technologies for surface treatment of materials without impairing bulk mechanical properties. The paper reviews the evolution of the microstructure of the surface layers of $\mathrm{Al}$ and Ti alloys, irradiated with LEHCEBs, as well as the characteristics of Al- and Ti-based surface alloys, synthesized by pulsed e-beam melting of film-substrate systems. Examples of improving the surface-sensitive properties of these alloys are also given.

\section{Aluminum Alloys}

In this Section, we present in detail the results originally published in [8]. Experimental samples were made of $\mathrm{Al}$ alloys: Al2024-T3 (Al-4.3 Cu-1.5 Mg, wt.\%), solution heat treated, cold worked and naturally aged, and Al6061-T6 (Al$0.6 \mathrm{Si}-0.7 \mathrm{Fe}$, wt.\%), solution heat treated and artificially aged. The previously electropolished samples were irradiated with 5 pulses in two different modes: (1) surface melting (pulse duration $\tau=0.8 \mu \mathrm{S}$, energy density $E s=5 \mathrm{~J} / \mathrm{cm}^{2}$ ); (2) intense melting with noticeable evaporation $(\tau=2.5 \mu \mathrm{S}$, Es $\left.=25 \mathrm{~J} / \mathrm{cm}^{2}\right)$. The characterization of the modified surface layers was performed by optical and scanning electron microscopy (SEM), X-ray diffraction (XRD) analysis, layer-by-layer transmission electron microscopy (TEM), and Auger electron spectroscopy (AES). The properties of the surface layers were examined by measuring corrosion resistance, microhardness, and wear resistance.

The results of numerical simulation of the characteristics of pulsed melting and resolidification for Al2024 alloy are given in Table 1 . Here, $x_{m}, t_{m}, v_{\mathrm{cr}}^{\max }, v_{c}^{\max }$, and $x_{\mathrm{ev}}$ are the thickness and lifetime of the melt, the maximum resolidification front velocity and the maximum cooling rate at this front achieved at the surface, and the thickness of the evaporated layer, respectively. These results are useable for Al6061 alloy since it has similar physical properties.

Both as-received $\mathrm{Al}$ alloys have an average grain size of $30-40 \mu \mathrm{m}$ and contain second-phase particles. After irradiation in the melting mode at the surface of Al6061 alloy, in contrast to Al2024 alloy, a numerous microcraters of diameter up to $\sim 70 \mu \mathrm{m}$ are formed. The thickness of molten layer is $7-10 \mu \mathrm{m}$, which agrees with numerical simulation.
The irradiation of both alloys in the evaporation mode leads to formation of a large-scale surface relief and increasing in the melt thickness up to $20-30 \mu \mathrm{m}$, which agrees with simulation as well. In case of Al2024 alloy, a grid of microcracks is formed at the irradiated surface. For Al6061 alloy, clear sliding traces are seen at the surface while cracking is absent. It follows that the thermoelastic stresses were induced by pulsed heating relieve by plastic deformation.

XRD analysis has shown that the irradiation of both $\mathrm{Al}$ alloys in both modes induces residual tensile stresses of $\sim 300 \mathrm{MPa}$ in a surface layer of thickness $\sim 10 \mu \mathrm{m}$, while in asreceived $\mathrm{Al}$ alloys, the compressive stresses of $\sim 70 \mathrm{MPa}$ were observed. The formation of residual tensile stresses at the surface was also observed at LEHCEBs irradiation of Fe and Mo samples [21]. This is due to fact that immediately after resolidification, the near-surface layers are under quasistatic thermoelastic compressive stresses induced by high thermal gradients during cooling. As result, the planar stress-strain state with a high dislocation density and residual tensile stresses is formed $[5,6]$.

According to TEM data, in the as-received Al2024 alloy, the second-phase particles of size from $\sim 200 \mathrm{~nm}$ to several micrometers are present in the matrix-phase grains and at their boundaries (Figure 1(a)). After irradiation in the melting mode in the $0.4-\mu \mathrm{m}$-thick surface layer, the grain structure remains almost unchanged, which suggest the possibility of its epitaxial regrowth. However, due to liquid-phase diffusion, a dissolving of both coarse $(\geq 1 \mu \mathrm{m})$ and fine second-phase particles has occurred. Subsequent resolidification followed by decay of an oversaturated solid solution leads to a resegregation of the second-phase particles of $\sim 60 \mathrm{~nm}$ in size, uniformly distributed inside the grains. Herein, the high dislocation density has retained, however, dislocations have been fixed around the secondphase particles (Figure 1(b)).

After irradiation of Al2024 alloy in the evaporation mode, complete dissolving of all coarse second-phase particles took place as well in a surface layer of thickness $\sim 1 \mu \mathrm{m}$. However, in the local regions of the $\sim 0.4-\mu \mathrm{m}$-thick nearsurface layer, a cellular structure has been formed. The cells are $200-300 \mathrm{~nm}$ in size, and a nanosized $\mathrm{CuAl}_{2}$ precipitates are observed at their boundaries (Figure 1(c)). Examination of the electron diffraction pattern (Figure 1(d)) has revealed that these precipitates are shaped as plates, and they grew along the (100) plates of the matrix lattice.

At a depth of $6-8 \mu \mathrm{m}$, the coarse particles are found again, and their edges are strongly fused, and they are surrounded by a cellular structure similar to that observed at the surface. It follows that cellular structure is formed in the local sites of the melt, where a concentration of alloying elements, due to liquid-phase dissolution of coarse secondphase particles, exceeds a certain critical value. Subsequent high-rate resolidification of the melt enriched by alloying elements followed by the decay of the supersaturated solid solution leads to the formation of non-disoriented structure consisting of submicron grains with nanosized $\mathrm{CuAl}_{2}$ precipitates coherently bound to the matrix and localized along the grain boundaries. The similar cellular structures are formed at pulsed e-beam melting of carbon and alloy 
TABLE 1: Characteristics of melting and resolidification of Al2024 alloy, irradiated with LEHCEBs.

\begin{tabular}{lcccccc}
\hline$E_{s}\left(\mathrm{~J} / \mathrm{cm}^{2}\right)$ & $\tau(\mu \mathrm{s})$ & $x_{m}(\mu \mathrm{m})$ & $t_{m}(\mu \mathrm{s})$ & $v_{\mathrm{cr}}^{\max }(\mathrm{m} / \mathrm{s})$ & $v_{c}^{\max }(\mathrm{K} / \mathrm{s})$ & $4 \times 10^{9}$ \\
\hline 5 & 0.8 & 9 & 4 & 18 & $x_{\mathrm{ev}}(\mu \mathrm{m})$ \\
25 & 2.5 & 35 & 60 & 10 & $4 \times 10^{9}$ & 2 \\
\hline
\end{tabular}

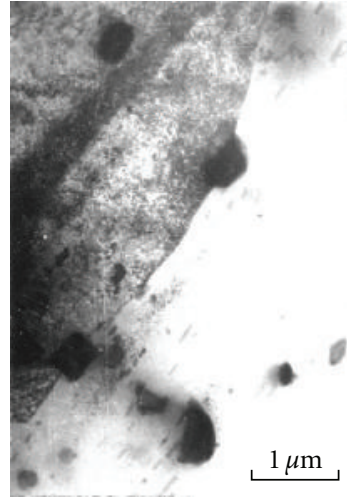

(a)

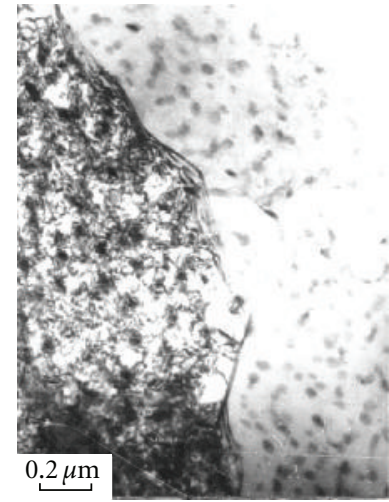

(b)

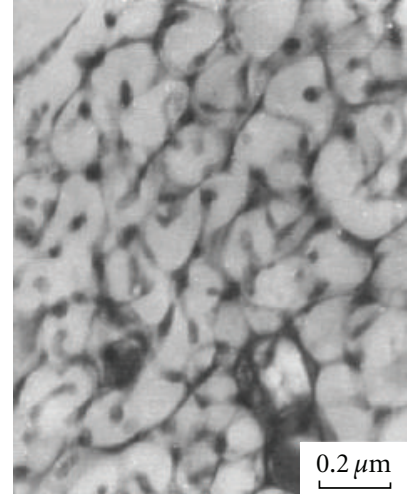

(c)

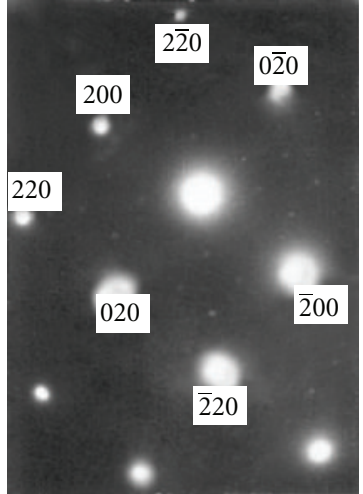

(d)

Figure 1: TEM images of the microstructure of the near-surface layer of Al2024 alloy before (a) and after irradiation in the melting (b) and evaporation (c) modes; (d) is electron-diffraction pattern for (c).

steels containing relatively coarse $(\geq 1 \mu \mathrm{m})$ globular carbide particles $[2,5,7]$.

According to the theory originally developed in [22] and proposed in [23], as applied to the nanosecond laser annealing of ion-implanted silicon, the formation of a cellular structure is due to the perturbation of the planar solid-liquid interface. This is associated with a large degree of constitutional supercooling of the melt when the destabilizing effect of the solute redistribution outweighs the stabilization provided by temperature gradients. With partition coefficient $k^{\prime}=C_{S} / C_{L}<1$, where $C_{S}$ and $C_{L}$ being the concentrations of alloying element in the solid and liquid phases, respectively, during resolidification, the alloying element will be pulled off the growing crystal into the melt and move into the near-surface layers. As a result, its concentration will peak at the surface. During the epitaxial resolidification of the near-surface layer enriched with the impurity, the latter is segregated from the supersaturated solid solution. This leads to the formation of cells separated by second-phase interlayers.

The dislocation structure near microcracks, which are formed under irradiation of Al2024 alloy in evaporation mode, is similar to that observed away from them. Examination of electrondiffraction patterns has revealed that the microcracks go along high-angle grain boundaries, which seem to have been grain boundaries in the as-received alloy. The surface cracking may be due to the formation of tensile stresses at the cooling and/or shrinkage of molten surface layer during resolidification. The second mechanism of cracking can be represented as follows. Resolidification starts from the solid substrate, herein, the orientation of the primary grains seems to be retained due to epitaxial regrowth. The grain core solidified first while the grain boundaries enriched with impurities are solidified at a lower temperatures, that is, later. As a grain solidifies, it shrinks, therefore, the grains "go away" from one another, and their boundaries fail to prevent this as they are in liquid state. As a result, microcracks are formed along the grain boundaries. The absence of the excess dislocation density and slip traces near the microcracks supports the possibility of this mechanism of cracking.

As-received Al6061 alloy, according to TEM data, contains dislocations decorated with fine $(\leq 20 \mathrm{~nm})$ secondphase precipitates and the dislocation density being rather high. The particles of size from $\sim 100 \mathrm{~nm}$ to several micrometers are presented also. The coarse particles, supposedly, belong to the $\mathrm{Al}_{2} \mathrm{CuMg}$ phase (Figure 2(a)).

After irradiation in the melting mode, spherical particles of diameter $0.5-1 \mu \mathrm{m}$ are seen at the surface (Figure 2(b)). These particles seem to have been formed as a result of the melting of coarse inclusions followed by the decay of an oversaturated solid solution during cooling. The character of the dislocation structure testifies to the dissolving of the $\sim 20 \mathrm{~nm}$ precipitates decorating dislocations. Also, $\sim 50 \mathrm{~nm}$ particles uniformly distributed throughout the grain bulk are observed. Their formation may be related to the decay of the oversaturated solid solution that has been formed by liquidphase dissolving of $100-500 \mathrm{~nm}$ particles in the matrix.

After irradiation of Al6061 alloy in the evaporation mode, a complete dissolving of all original second-phase particles and precipitates has occurred in the near-surface layer (Figure 2(c)). AES analysis has shown that the dissolving has not changed the concentration of the alloying elements in the near-surface layer. However, at the surface, a homogeneous $\mathrm{Al}_{2} \mathrm{O}_{3}$ film of thickness $\sim 30 \mathrm{~nm}$ has formed while in asreceived alloy, the thickness of such film varies from 5 to $40 \mathrm{~nm}$. In whole, these data suggest that the dissolving of second-phase particles by pulsed melting leads to the 


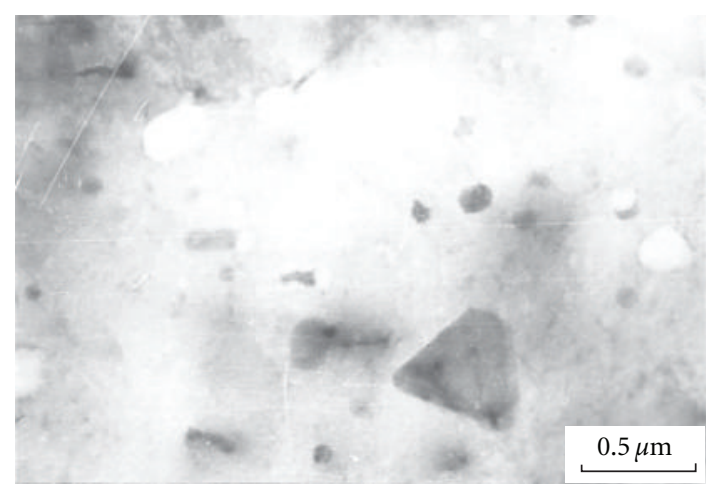

(a)

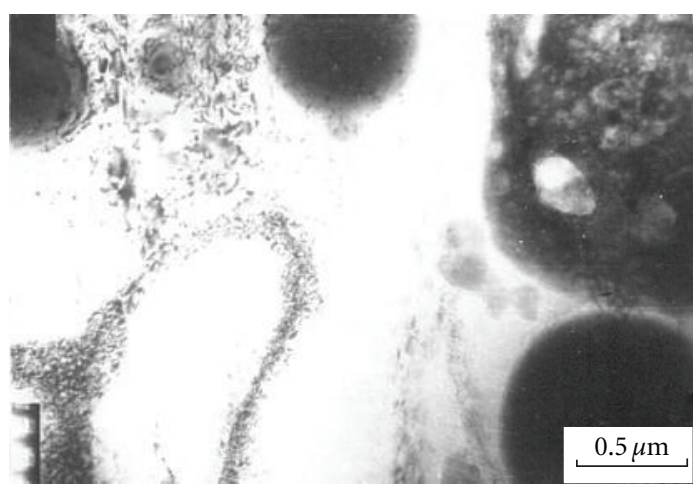

(b)

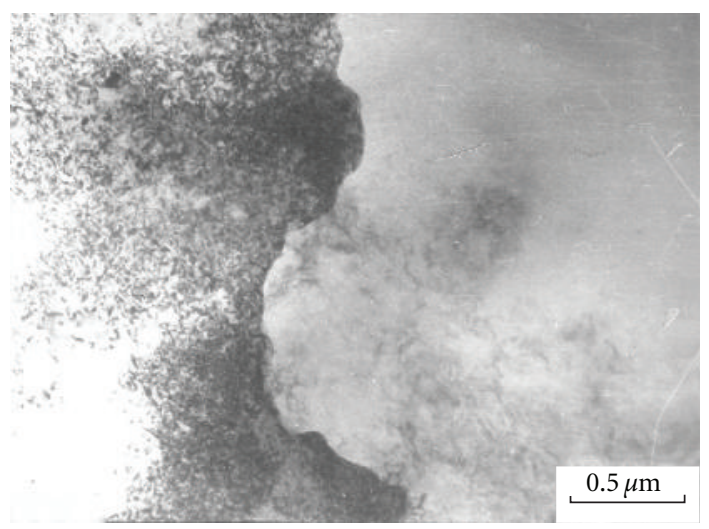

(c)

Figure 2: TEM images of the microstructure of the near-surface layer of Al6061 alloy before (a) and after irradiation in the melting (b) and evaporation (c) modes. Newly formed spherical second-phase particles and residual fragments of original coarse particles are seen in (b).

formation of a single-phase oversaturated solid solution in the near-surface layer. Estimates based on a comparison of the diffusion length with the size of the original secondphase particles suggest that the dissolving of these particles take place due to the liquid-phase diffusion of the alloying element in liquid $\mathrm{Al}$.

Since second-phase particles determine the corrosion behavior of a material, their dissolving should increase substantially the corrosion resistance. The corrosion resistance measurements for Al6061 alloy provide strong support for this supposition (Figure 3). The data for high-purity $\mathrm{Al}(99.999 \% \mathrm{Al})$ are given for comparison. A certain contribution to the enhancement of the corrosion resistance is made by the protective $\mathrm{Al}_{2} \mathrm{O}_{3}$ film formed after irradiation. For Al2024 alloy, as distinct from Al6061 alloy, irradiation has not increased the corrosion resistance. This is related to the incomplete dissolving of second-phase particles under pulsed melting and to the formation of microcracks.

Irradiation of Al2024 and Al6061 alloys in both modes leads to enhancement of microhardness (Figure 4) and wear resistance (Figure 5) of the surface layers. The nonmonotonic microhardness-depth profiles are associated with the strain hardening induced by quasistatic stresses and stress waves followed by partial recovery in the heat-affected zone.

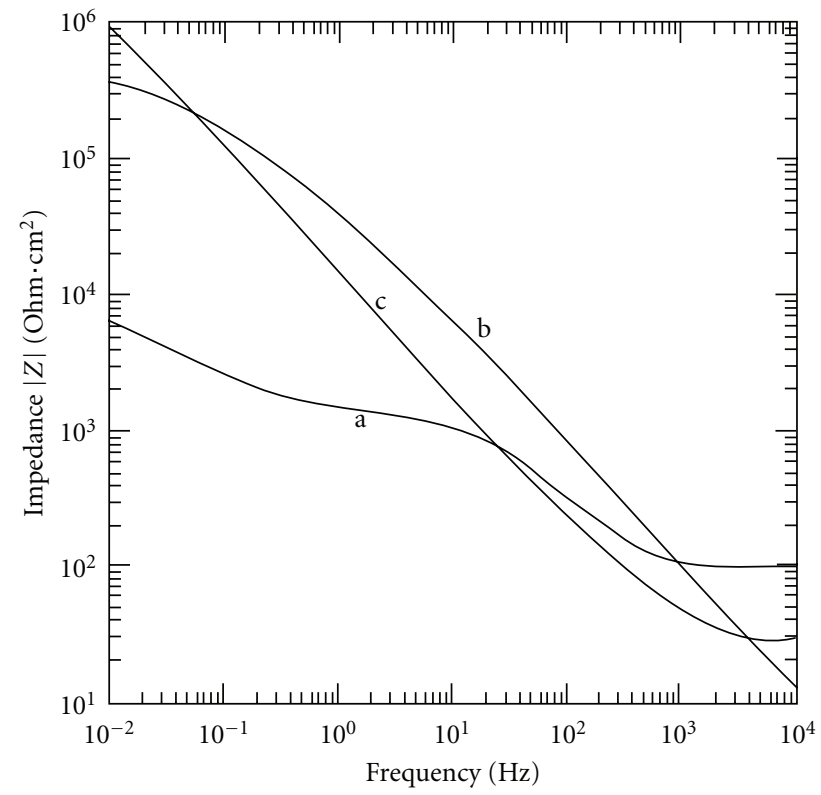

FIgURE 3: Bode magnitude plots for: (a) as-received Al6061 alloy; (b) Al6061 alloy, irradiated in the evaporation mode; (c) $99.999 \%$ $\mathrm{Al}$ exposed to aerated $0.5 \mathrm{M} \mathrm{NaCI}$ solution for 24 hours. 


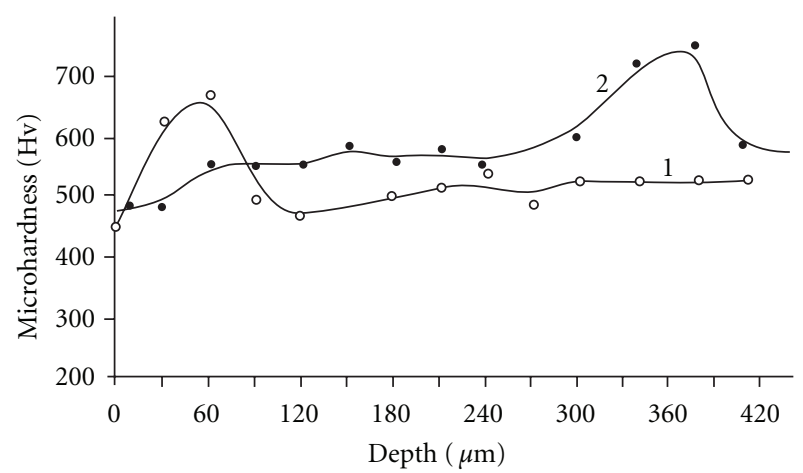

FIgURE 4: Microhardness depth profiles for Al2024 alloy specimens irradiated in the melting (1) and evaporation (2) modes. Initial microhardness $(\mathrm{Hv})$ is $490 \mathrm{MPa}$. Load is $0.5 \mathrm{H}$.

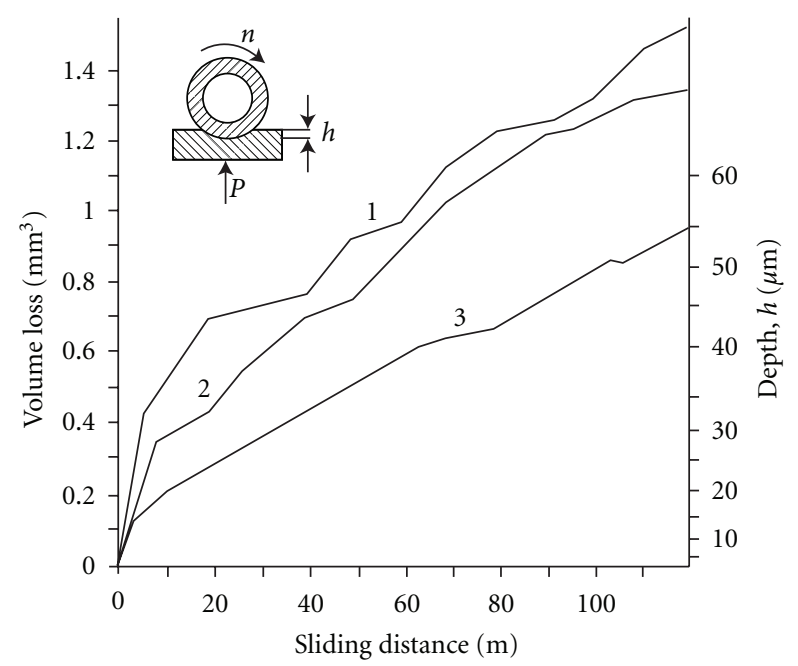

Figure 5: Volume loss versus sliding distance for Al2024 alloy samples: (1) as-received; (2 and 3) after irradiation in melting and evaporation modes, correspondently. Wear tests were performed in dry conditions using a block-on-ring configuration with Al2024 alloy sliding against steel 52100 (HRC 62), ring diameter $35 \mathrm{~mm}$; $55 \mathrm{rev} / \mathrm{min} ; P=100 \mathrm{~N}$.

\section{Titanium Alloys}

In the first experiments $[24,25]$ on surface cold working samples made of $\mathrm{Ti}(\alpha+\beta)$ alloys it was found that multiple LEHCEB melting leads to a decrease in the surface roughness up to $0.1 \mu \mathrm{m}$ and the formation of $\sim 5 \mu \mathrm{m}$-thick "white" layer (Figure 6). Later, these results were used for the development of high technology of surface finish of metallic dentures [26]. It was also established that pulsed melting and high-rate $\left(\sim 10^{9} \mathrm{~K} / \mathrm{s}\right)$ quench from the melt leads to the dissolution of $\beta$-phase and the formation of martensite phases. However, as a result of irradiation the residual tensile stresses are formed in the surface layers, and microcraters are appeared at the top surface, which are stress risers.

By choosing the optimum beam energy density and pulse number the surface cratering can be suppressed. In turn, the subsequent vacuum annealing allows one to remove the residual stresses and to form the equilibrium structure. As

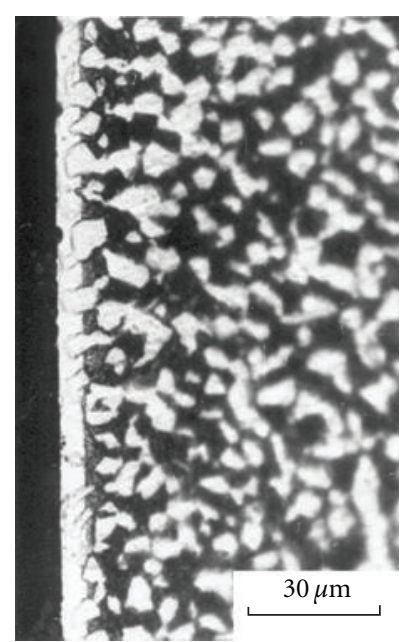

(a)

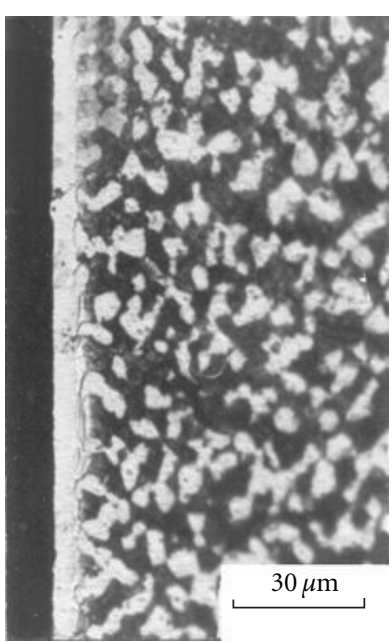

(b)
Figure 6: Cross-section microstructure of $(\alpha+\beta)$ Ti alloy (Ti-6.9 Al-3.3 Mo-1.7 Zr) irradiated with LEHCEBs $\left(2.5 \mu \mathrm{s}, 5 \mathrm{~J} / \mathrm{cm}^{2}\right)$ : (a) $n=5$; (b) $n=40$.

a result, multiple pulsed melting followed by subsequent vacuum annealing allows one to improve the mechanical properties of Ti alloys, including fatigue strength and fatigue life $[2,24,25]$. Thus, in case of Ti alloys, the main tasks are to avoid the surface cratering and to achieve the stress relief.

The main reason of cratering is a local overheating and melting of second-phase particles [5, 6, 27]. In turn, the formation of residual tensile stresses is associated with the high thermal gradients in the surface layers during the cooling $[5,6]$. It follows that to reduce the cratering and for removal of the residual stresses, it is reasonable to increase lifetime of the melt and to decrease thermal gradients. This approach was realized in [28] by increasing the initial temperature of the irradiated samples.

Experimental samples were made of the Ti- $6 \mathrm{Al}-4 \mathrm{~V}$ alloy, solution annealed at $920^{\circ} \mathrm{C}$ for $2 \mathrm{~h}$ and aged at $550^{\circ} \mathrm{C}$ for $4 \mathrm{~h}$. Prepolished samples were irradiated with LEHCEB in Ar plasma at a pressure of $3 \cdot 10^{-2} \mathrm{~Pa}$ at pulse duration $3 \mu \mathrm{s}$, energy density $2.5 \pm 0.7 \mathrm{~J} / \mathrm{cm}^{2}$, pulse number $n=$ 40 , and repetition rate $0.1 \mathrm{~Hz}$. The treatment mode was corresponded to the initial surface melting, and it was chosen as the optimum based on $[24,25]$. The initial temperature of irradiated samples $T_{0}$, measured by thermocouple, was RT, 200, 400, and $550^{\circ} \mathrm{C}$ with accuracy within of $\pm(3-10)^{\circ} \mathrm{C}$. The heater made of $\mathrm{NiCr}$ wire was located just behind the irradiated sample. After irradiation, the initial temperature $T_{0}$ was maintained for $5 \mathrm{~min}$. During this time, an inlet of Ar was stopped, the chamber was pumped up to a pressure of $\sim 10^{-4} \mathrm{~Pa}$ whereupon the heater was switched off. After cooling of the sample down to $200^{\circ} \mathrm{C}$, the pumping was stopped, and then the sample was cooled down to RT at a pressure of $<10^{-1} \mathrm{~Pa}$.

Selected samples, irradiated at RT, were subjected to vacuum $\left(\sim 10^{-4} \mathrm{~Pa}\right)$ annealing $\left(550^{\circ} \mathrm{C}, 2 \mathrm{~h}\right)$. The characterization of the modified surface layers was performed by laser microscopy, SEM, XRD, and AES. The properties of 
the surface layers were examined by measuring corrosion resistance, microhardness, and wear resistance.

According to numerical simulation, at $3.2 \mathrm{~J} / \mathrm{cm}^{2}$ (the upper limit of energy density), the increasing of the initial temperature from $\mathrm{RT}$ to $550^{\circ} \mathrm{C}$ leads to an increase in the melt thickness and melt lifetime in the range of 1.2$2.5 \mu \mathrm{m}$ and $\sim 1-5 \mu \mathrm{s}$, correspondently. In turn, the thermal gradients in the heat-affected zone in the range, including the martensite start temperature $\left(\sim 800^{\circ} \mathrm{C}[29]\right)$, decreases by 1-2 orders of magnitude. This should lead to a noticeable decrease in the level of quasistatic and, therefore, residual stresses.

The Ti- $6 \mathrm{Al}-4 \mathrm{~V}$ alloy in the initial state consists of a globular $\alpha$-phase grains $(\sim 5 \mu \mathrm{m})$ separated by layers of $\beta$ phase. Figure 7 shows images of the surface morphology of samples, irradiated at different initial temperatures.

At pulsed melting at RT and $200^{\circ} \mathrm{C}$, the lamellar microrelief is formed within the $\alpha$-grains (Figures $7(\mathrm{~b})$ and $7(\mathrm{c}))$. This is associated with martensitic transformation, which takes place in the $(\alpha+\beta)$ Ti alloys, quenched from the $\beta$-phase field. The second reason may be the plastic deformation by sliding under compressive (parallel to the surface) quasistatic stresses formed after resolidification. Really, in [3], it was shown for Fe target, irradiated in the premelting mode $\left(2 \mu \mathrm{s}, 2.5 \mathrm{~J} / \mathrm{cm}^{2}\right)$, that the quasistatic stresses can reach a few $\mathrm{GPa}$, that is, to exceed significantly the yield stress of the material. And finally, the microrelief may be formed by the secondary $\alpha$-plates due to full decay of retained $\beta$-phase. At $400^{\circ} \mathrm{C}$, this process is almost completed, so, the secondary $\alpha$-plates does not occurred (Figure 7(d)).

From Figure 7(a), it follows that after pulsed melting at $\mathrm{RT}$ the grain size is close to the initial one. This allows one to conclude that this structure is formed by the epitaxial resolidification on the solid substrate. With increasing the initial temperature, the grain coarsening is observed (see Figure 7). Grain growth seems to be associated with dynamic recrystallization because the surface layer quenched from the melt undergoes simultaneous action of compressive quasistatic stresses and heat treatment during cooling.

Single microcraters of diameter up to $\sim 100 \mu \mathrm{m}$ are presented at the irradiated surface. Typical microcraters and corresponding profilograms are shown in Figure 8. As it follows from the profilograms, even at relatively large diameter of microcrater $(\sim 70 \mu \mathrm{m})$, its depth is $\leq 2 \mu \mathrm{m}$. Thus, microcraters formed under these treatment conditions are relatively flat defects. Cratering probability does not depend on the initial temperature of the irradiated samples. According to SEM/EDX, microcraters contain increased content of oxygen, which agrees with [24].

Pulsed melting leads to an increase in surface roughness, which agrees with SEM (Figure 7). With increasing the initial temperature, the surface roughness increases, reaching $0.12 \mu \mathrm{m}$ at $550^{\circ} \mathrm{C}$. This can be explained by a large difference in deformation of neighboring grains, caused by the thermal expansion anisotropy of Ti. Maximum surface roughness ( $\mathrm{Ra}$ $\sim 0.2 \mu \mathrm{m}$ ) was found to be at pulsed melting at RT followed by vacuum annealing, which may be associated with long duration of annealing.
According to AES, the unirradiated surface contains $\sim 50$ at. $\%$ oxygen and $\sim 20$ at. $\%$ carbon. High concentration of oxygen indicates the presence of a thin $\mathrm{TiO}_{2}$ oxide film. The thickness of the surface layer, saturated with oxygen, is about $40 \mathrm{~nm}$. After irradiation at RT and $200^{\circ} \mathrm{C}$, the thickness of this layer decreases about 2-fold (Figure 9), which indicates its cleaning from oxygen. At $T_{0} \geq 400^{\circ} \mathrm{C}$, by contrast, the saturation of surface layers with oxygen is observed. The same effect but an even greater degree takes place after irradiation at RT followed by vacuum annealing (see Figure 9). It is obvious that this is due to the diffusion of oxygen from the residual gases of vacuum chamber at elevated temperatures and prolonged exposure. It can be assumed that multiple pulsed melting contributes to the growth of oxygen diffusivity through the growing density of quenched-in vacancies and dislocations in the surface layer $[5,6]$.

The AES depth profiles of carbon are limited by $\sim 10 \mathrm{~nm}$ depth, and with increasing the initial temperature, these profiles remain almost unchanged compared to the initial state.

Figure 10 shows the XRD patterns of Ti-6Al-4V alloy before and after LEHCEBs treatment in the different modes, recorded at incident angle $1^{\circ}$, which corresponds to the depth of the analyzed layer of $0.14 \mu \mathrm{m}$. The diffraction patterns, recorded at angles $\leq 8^{\circ}$ for which the analyzed depth is $\leq 1.5 \mu \mathrm{m}$ are the same. In the initial state, Ti-6Al-4V alloy is composed of $\alpha$ - and $\beta$-phases. After pulsed melting at $T_{0} \leq 400^{\circ} \mathrm{C}$, the reflections of $\beta$-phase become very weak, which indicates its dissolution.

Irradiation at $\mathrm{RT}$ and $200^{\circ} \mathrm{C}$ leads to a broadening of $\alpha$ phase peaks, occurrence of double peak (110) $\alpha$ and a shift of $\alpha$-phase peaks to higher angles. This indicates the formation of martensite phases, the growth of microstresses, and the formation of residual tensile stresses, which is in agreement with $[24,25]$.

After irradiation at 400 and $550^{\circ} \mathrm{C}$, the broadening of $\alpha$ phase peaks and its shift almost is not observed. Therefore, increasing the initial temperature leads to a reduction of microstresses, almost complete removal of residual tensile stresses, as well as suppress ion of the martensitic transformation. The later agrees with the fact that at the quenching at increased initial temperatures, the martensitic $\beta \rightarrow$ $\alpha^{\prime}$ transformation must be incomplete compared to that realized at RT. The suppression of the martensitic transformation at elevated initial temperatures indicates that the surface microrelief observed at irradiation at RT and $200^{\circ} \mathrm{C}$ (Figures 7(b) and 7(c)) has mostly a martensitic nature. The postirradiation vacuum annealing, as well as irradiation at 400 and $550^{\circ} \mathrm{C}$, leads to removal of the micro- and residual stresses and to the decay of the martensitic phases in agreement with $[24,25]$.

The change in the surface microhardness Hv depending on LEHCEB treatment mode is presented in Table 2. After irradiation at RT, the microhardness varies slightly. With increasing the initial temperature, microhardness increases monotonically, reaching at $550^{\circ} \mathrm{C} \mathrm{Hv} \sim 5 \mathrm{GPa}$, that is, $\sim 1.5$ times higher than that of original state. After irradiation 


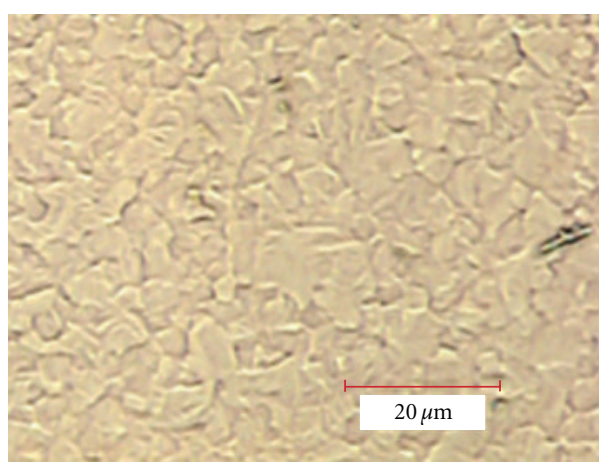

(a)

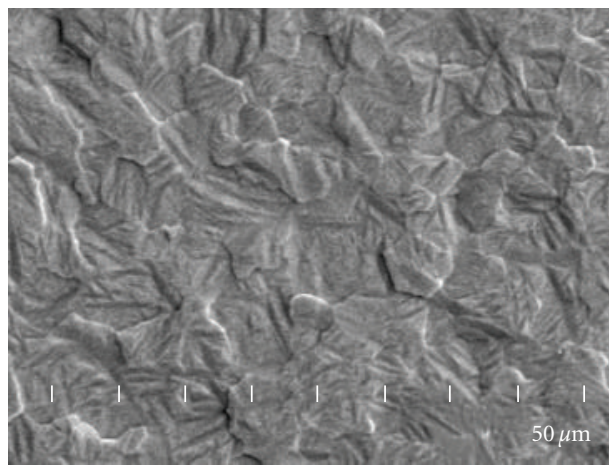

(c)

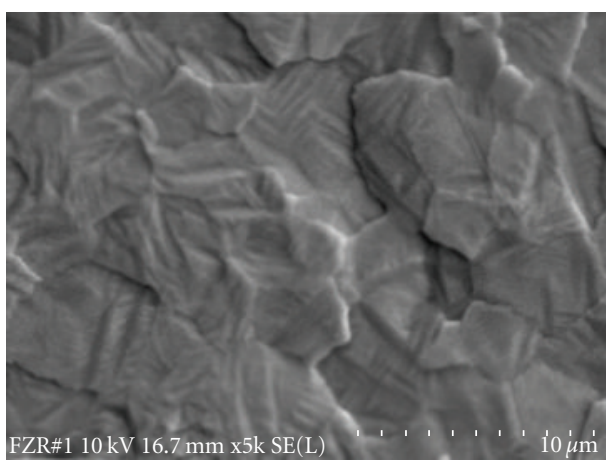

(b)

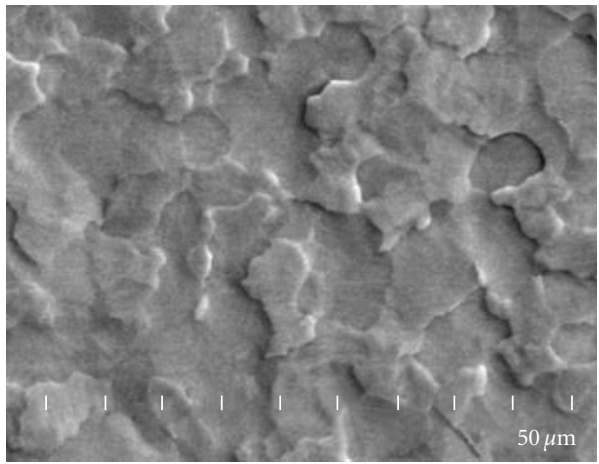

(d)

Figure 7: Micrographs of the surface of the Ti-6Al-4V samples, irradiated at RT (a, b), 200 (c) and $400^{\circ} \mathrm{C}$ (d); (a) laser microscopy, (b, c, d) SEM.

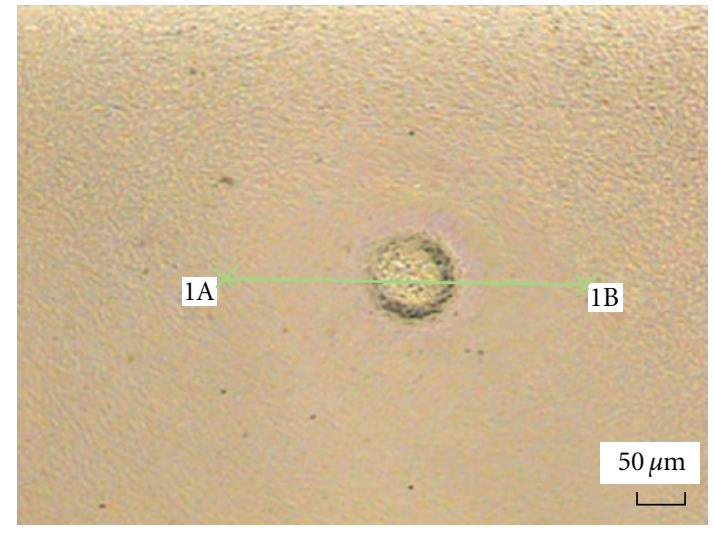

(a)

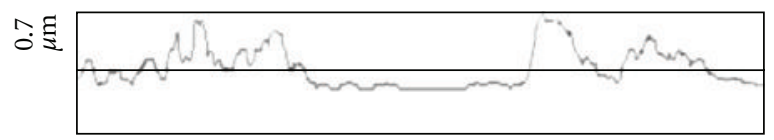

(c)

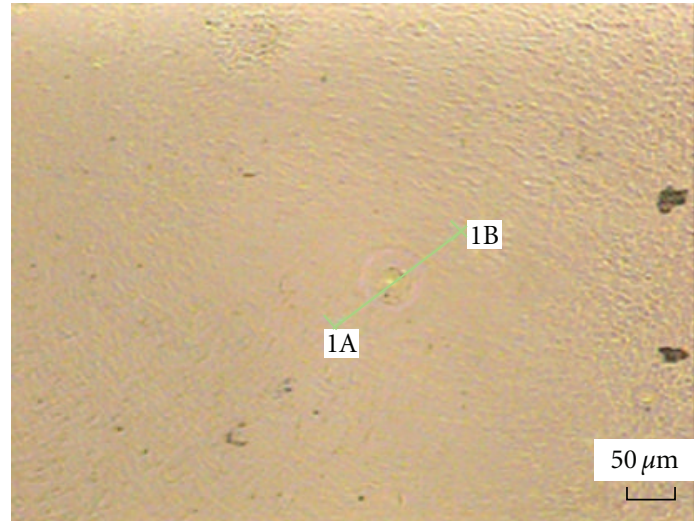

(b)

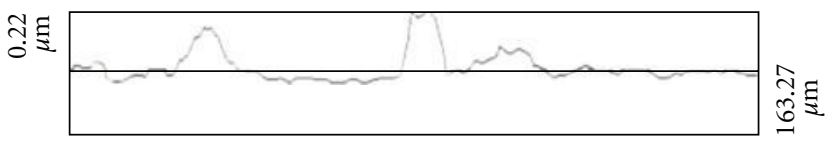

(d)

Figure 8: Micrographs and profilograms of the surface of Ti-6Al-4V alloy samples, irradiated at RT (a, c) and $550^{\circ} \mathrm{C}$ (b, d). Laser microscopy.

at RT followed by annealing, the surface microhardness is $\sim 4 \mathrm{GPa}$. Note that since, the contact depth was $1.5-2 \mu \mathrm{m}$, these data reflect the hardness of the surface layers quenched from the melt, as well as underlayers, subjected to pulsed heating in the solid state.
As follows from XRD data, the increase in the surface microhardness with increasing initial temperature, as well as after irradiation at RT followed by annealing is associated with removal of residual tensile stresses induced by pulsed heating. In addition, as follows from AES data, the 
TABLE 2: Surface microhardness of Ti-6Al-4V alloy samples before and after LEHCEBs irradiation at different initial temperatures.

\begin{tabular}{lccr}
\hline LEHCEB treatment mode & & Microhardness Hv $(\mathrm{GPa})$ & $P=0.2 \mathrm{H}$ \\
\hline Untreated & $P=0.1 \mathrm{H}$ & $2.8 \pm 0.2$ & $3.0 \pm 0.2$ \\
LEHCEB $(\mathrm{RT})$ & $2.5 \pm 0.2$ & $3.4 \pm 0.2$ & $2.9 \pm 0.2$ \\
LEHCEB $\left(200^{\circ} \mathrm{C}\right)$ & $3.6 \pm 0.2$ & $3.3 \pm 0.3$ & $3.7 \pm 0.3$ \\
LEHCEB $\left(400^{\circ} \mathrm{C}\right)$ & $4.1 \pm 0.3$ & $4.8 \pm 0.3$ & $4.1 \pm 0.3$ \\
LEHCEB $\left(550^{\circ} \mathrm{C}\right)$ & $4.3 \pm 0.3$ & $5.0 \pm 0.3$ & $4.7 \pm 0.3$ \\
LEHCEB $(\mathrm{RT})+$ annealing & $5.7 \pm 0.3$ & $4.1 \pm 0.3$ & $4.6 \pm 0.3$ \\
\hline
\end{tabular}

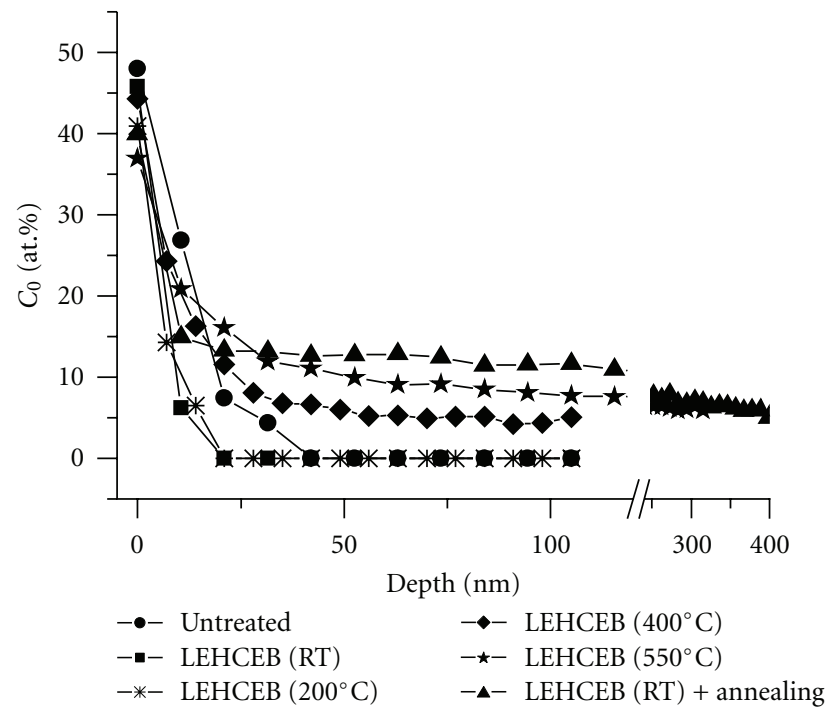

FIGURE 9: AES depth profiles of oxygen for Ti-6Al-4V samples before and after LEHCEBs irradiation at different initial temperatures.

microhardness can increase due to the formation of $\mathrm{TiO}_{2}$ precipitates because of saturation of the surface layers with oxygen (dispersion hardening), as well as due to increasing the concentration of oxygen in the $\alpha$-solid solution (solidsolution hardening).

It is important to note that the microhardness of the irradiated surface significantly depends on the initial state of the Ti alloy. In contrast to annealed Ti-6Al-4V samples, mentioned above, in the case of preliminary surface cold working samples made of the $(\alpha+\beta)$ Ti alloy with a relatively high initial microhardness $(\sim 400 \mathrm{MPa})$, multiple pulsed melting at RT results in a decrease in the surface microhardness $[24,25]$, which is most likely associated with the softening due to residual tensile stresses.

The results of wear tests for Ti-6Al-4V samples before and after LEHCEB treatment at different initial temperatures are shown in Figure 11. The pulsed melting at $T_{0} \leq$ $400^{\circ} \mathrm{C}$ leads to decreasing the wear resistance, particularly at high sliding distance. Maximum wear (top right point) corresponds to the track depth of $\sim 18 \mu \mathrm{m}$, that is, wear take place within the heat-affected zone. In contrast, irradiation at $550^{\circ} \mathrm{C}$, as well irradiation at RT followed by annealing leads to a significant increase in wear resistance. In the first case, volume loss at maximum sliding distance decreased by 50 times compared to the initial state; in the second case, any wear loss is not fixed by method used. Increase in the wear resistance of the Ti-6Al-4V alloy, LEHCEB-treated in the above-mentioned modes correlates with an increase in the surface microhardness (Table 1) and stress relief.

Figure 12 shows the potentiodynamic polarization curves for Ti-6Al-4V alloy before and after LEHCEB treatment at different initial temperatures. It is seen that after irradiation in all modes, the corrosion current density decreases, which indicates the increasing corrosion resistance. This agrees with "white" layer revealed on the cross section after chemical etching (Figure 6). The corrosion behavior at RT and $200^{\circ} \mathrm{C}$ are the same. At initial temperature of $\leq 200^{\circ} \mathrm{C}$ and $550^{\circ} \mathrm{C}$, a slight decrease in corrosion potential as compared to the initial state is observed. In turn, after irradiation at $400^{\circ} \mathrm{C}$, the corrosion potential shifts positively, which testifies on increased passivation and corrosion resistance of the material [30]. According to XRD (Figure 10), this effect may be connected with the formation of the single-phase ( $\alpha$-solid solution) structure in the near-surface layer.

\section{Aluminum- and Titanium-Based Surface Alloys}

Liquid-phase mixing of film-substrate systems with pulsed intense $\left(10^{-8}-10^{-6} \mathrm{~s}, 10^{6}-10^{8} \mathrm{~W} / \mathrm{cm}^{2}\right)$ laser $[31,32]$, electron $[5,6,12,33]$ and ion [34] beams, as well as plasma flows $[35,36]$ is an efficient method for the formation of surface alloys. Unlike the commonly used PVD and CVD thinfilm techniques, this method is free from problems of poor film adhesion and delamination. It has been established in experiments on binary systems that the method allows forming the metastable oversaturated solid solutions resulted from a high-rate quenching from the melt as well as synthesis of metal silicides $[31,33]$. A thickness of the alloyed layer is $\geq 1 \mu \mathrm{m}$, that is, several times higher than that of the highdose ion implantation [31]. From the practical point of view, LEHCEBs of duration $\sim 10^{-6} \mathrm{~s}$ have the advantage over nanosecond laser and electron beams [31] as they offer the possibility to produce surface alloys of greater thickness with lower residual stresses.

This section reviews briefly the investigations of characteristics of Al- and Ti-based surface alloys, synthesized 


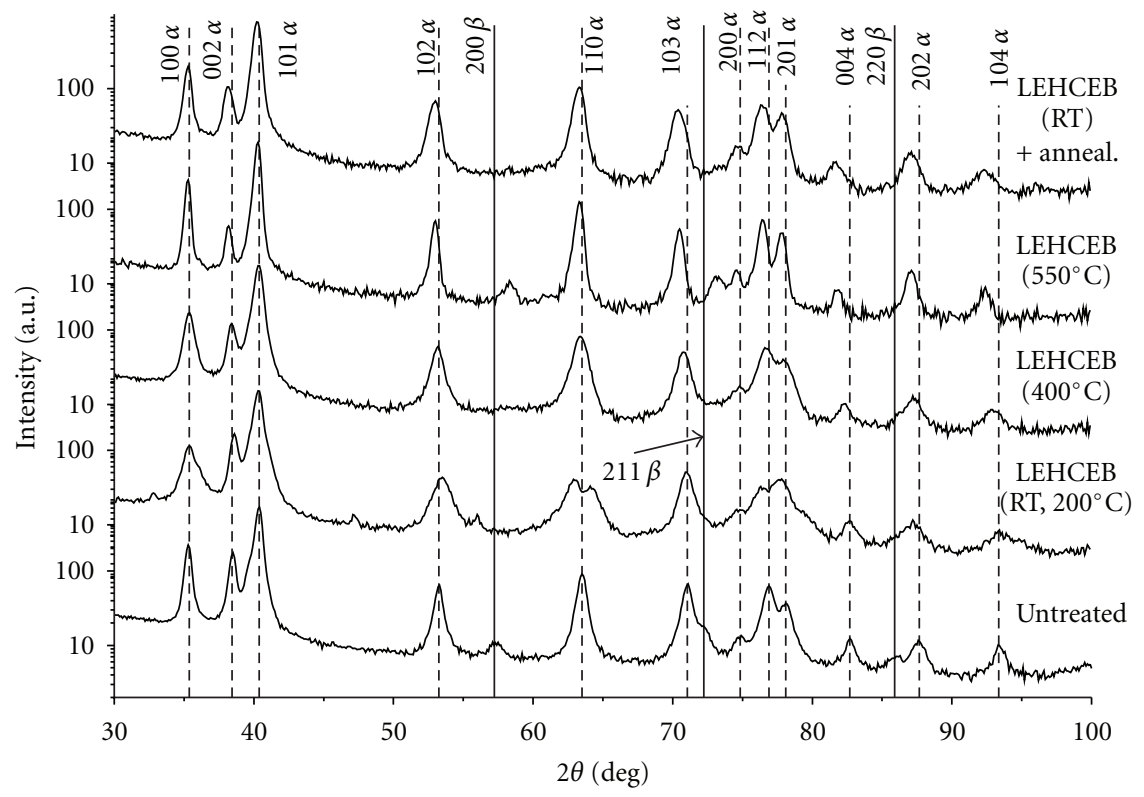

FIGURE 10: XRD patterns of Ti-6Al-4V alloy samples before and after LEHCEB irradiation at different initial temperatures. Incident angle is $1^{\circ}$.

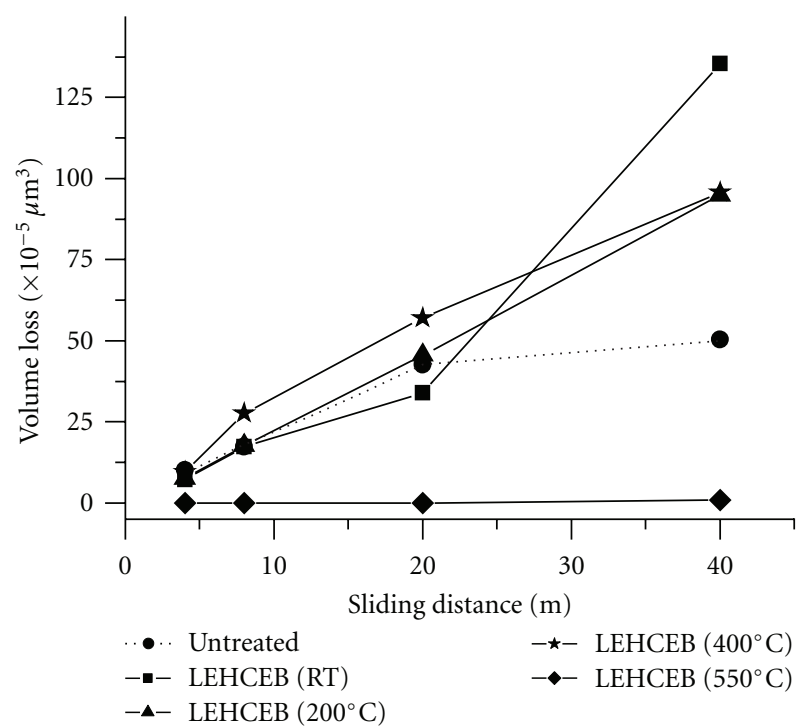

FIGURE 11: Volume loss versus sliding distance for Ti-6Al-4V alloy samples before and after LEHCEB irradiation at different initial temperatures. Wear tests were performed in dry conditions using a ball-on-plate configuration with Ti-6Al-4V alloy sliding against steel $100 \mathrm{Cr} 6$, ball diameter $5 \mathrm{~mm} ; P=0.6 \mathrm{~N}$, sliding rate $0.015 \mathrm{~m} / \mathrm{s}$.

by LEHCEB pulsed melting of multilayer film-substrate systems, namely, $[\mathrm{Al} / \mathrm{Si}] / \mathrm{Al},[\mathrm{Al} / \mathrm{C}] / \mathrm{Al},[\mathrm{Zr} / \mathrm{Ti}] / \mathrm{Ti}-6 \mathrm{Al}-4 \mathrm{~V}$, and $\mathrm{Al} / \mathrm{Ti}$ systems.

4.1. Multilayer [Al/Si]/Al, [Al/C]/Al Systems. Al-Si and Al$\mathrm{C}$ systems are of interest owing to dissimilar components with a very low solid solubility. Al-C system is insoluble in a liquid state also. In the original state, the multilayer

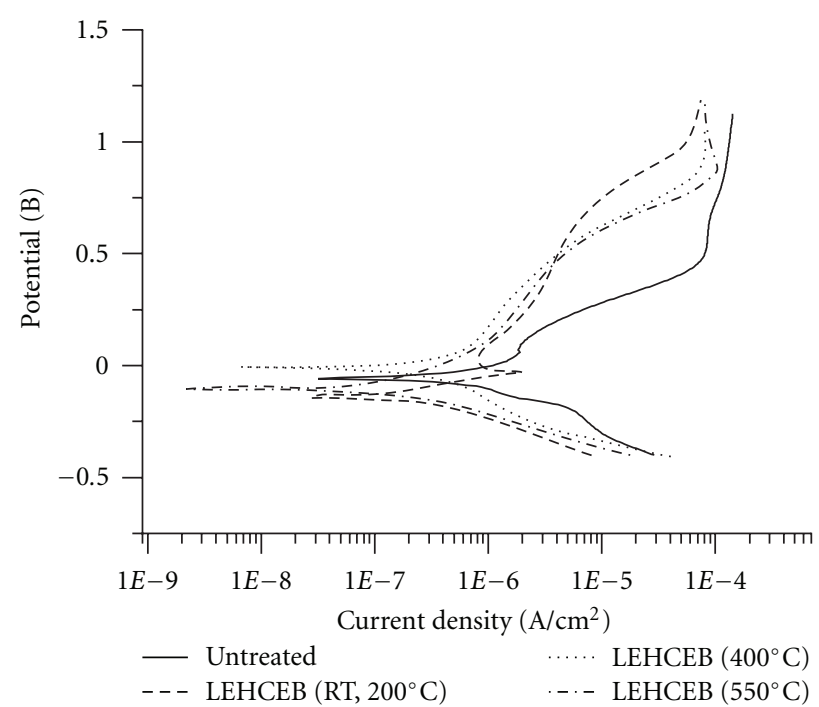

Figure 12: Potentiodynamic polarization curves for Ti-6Al-4V alloy samples in $1 \% \mathrm{NaCl}$ solution before and after LEHCEB irradiation at different initial temperatures.

(Al/Si/Al/Si/Al/Si/Al) structure prepared on an $\mathrm{Al}$ substrate by magnetron deposition consists of four polycrystalline Al layers $(\sim 350 \mathrm{~nm})$ separated with three amorphous $\mathrm{Si}$ interlayers $(\sim 50 \mathrm{~nm})$. According to AES data, carbon (up to 5 at.\%) is present at the $\mathrm{Al} / \mathrm{Si}$ interfaces. After irradiation in the mode of melting of the Al layers, but below the melting threshold of $\mathrm{Si}\left(2.5 \mu \mathrm{s}, 2.3-3.1 \mathrm{~J} / \mathrm{cm}^{2}\right.$, pulse number $n=1$ ), the multilayered structure is retained. However, the concentration of $\mathrm{Si}$ in the Al layers increases abruptly due to the diffusion of $\mathrm{Si}$ atoms into the liquid Al. The rapid resolidification of the Si-enriched Al layers from 


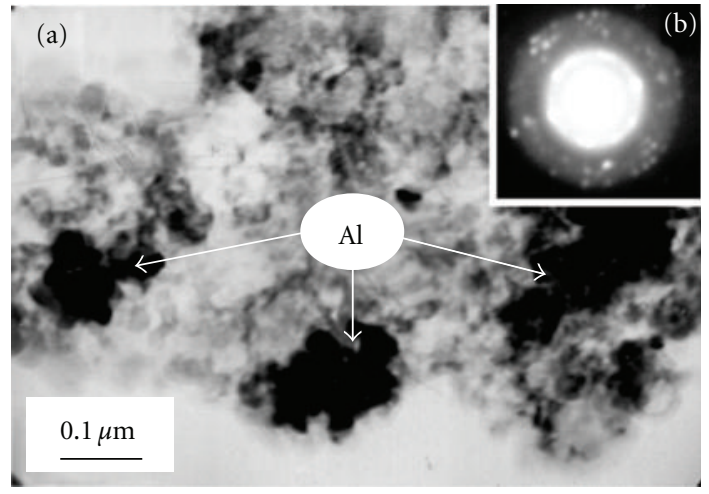

FIGURE 13: TEM image of a multilayer (Al/Si/Al/Si/Al/Si/Al) system on an $\mathrm{Al}$ substrate after pulsed melting of Al layers: (a) bright-field image, (b) diffraction pattern $\left(2.5 \mu \mathrm{s}, 2.3 \mathrm{~J} / \mathrm{cm}^{2}, n=1\right)$.

melt results in the formation of nanosized $(\sim 30 \mathrm{~nm}) \mathrm{Al}$ subgrains combined in $\sim 100 \mathrm{~nm}$ complexes. At the Al subgrain boundaries, the nanosized second-phase (Al4Si2C5) precipitates are segregated (Figure 13). In the amorphous $\mathrm{Si}-$ $\mathrm{Al}-\mathrm{C}$ interlayers, partial crystallization with the formation of nanosized Si particles takes place. As the melting threshold for $\mathrm{Si}$ is achieved $\left(\geq 4 \mathrm{~J} / \mathrm{cm}^{2}\right)$, the efficiency of mixing decreases abruptly because of the ablation of the coating $[5,6]$.

The as-prepared $(\mathrm{Al} / \mathrm{C} / \mathrm{Al} / \mathrm{C}) / \mathrm{Al}$ system consists of two alternating polycrystalline Al layers $(\sim 700$ and $\sim 500 \mathrm{~nm})$ and two amorphous carbon layers ( $\sim 200$ and $\sim 100 \mathrm{~nm})$ deposited on an $\mathrm{Al}$ substrate. After irradiation in the mode of melting of the Al layers $\left(2.5 \mu \mathrm{s}, 1.8 \mathrm{~J} / \mathrm{cm}^{2}\right)$, the following structures are formed: coarse (up to $\sim 20 \mu \mathrm{m}$ ) moltenoff $\mathrm{Al}$ particles; regions consisting of submicron $\mathrm{Al}$ grains with nanosized $(2-3 \mathrm{~nm})$ particles of cubic-lattice carbon segregated along the grain boundaries; regions consisting of 50-100 nm cells of amorphous carbon with nanosized (3$5 \mathrm{~nm}) \mathrm{Al}$ segregates which are the major type of structures (Figure 14) and finally, amorphous carbon particles (a few micrometers in size) formed on destruction of the original carbon layers. The formation of these structures points to the stratification of $\mathrm{Al}$ and $\mathrm{C}$ on pulsed melting under the given conditions. As distinct from the previous system, the second phases $\left(\mathrm{Al}_{4} \mathrm{C}_{3}\right)$ are absent, which may be related to the rather low temperature $\left(<1700^{\circ} \mathrm{C}\right)$ and short lifetime $\left(\sim 10^{-6} \mathrm{~s}\right)$ of the $\mathrm{Al}$ melt $[5,6]$.

In whole, the results obtained suggest the possibility of using this method for the synthesis of nanocrystalline surface alloys consisting of insoluble components. Nonuniform mixing as well as the presence of undissolved particles is associated with the fact that the thickness of as-deposited layers was comparable or greater than the liquid-phase diffusion length. To ensure a uniform liquid-phase mixing of film-substrate system, it is necessary to meet two main conditions: (1) diffusion length, which depends on a melt lifetime, must be much more than a thickness of the solid film; (2) e-beam energy density should not exceed the threshold of film evaporation. These conditions were taken into account at fabrication of Ti-based surface alloys.

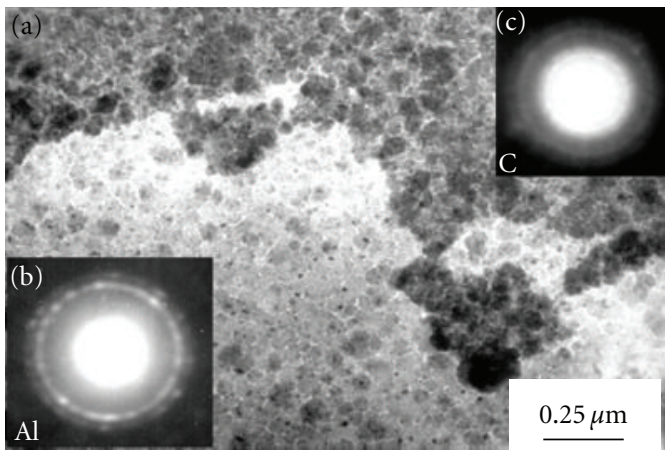

FIGURE 14: TEM image of a multilayer $(\mathrm{Al} / \mathrm{C} / \mathrm{Al} / \mathrm{C})$ system on an $\mathrm{Al}$ substrate after pulsed melting of Al layers: (a) bright-field image, (b, c) diffraction patterns for bottom and top parts of (a), respectively, $\left(2.5 \mu \mathrm{s}, 1.8 \mathrm{~J} / \mathrm{cm}^{2}, n=1\right)$.

4.2. Multilayer [Zr/Ti]/Ti-6Al-4V System. Ti-6Al-4V alloy has been widely used for surgical implants, like artificial and other joints due to high specific strength, corrosion resistance, bio-, and mechanical compatibility. However, its wear resistance is relatively low. During cyclic loading of implant, a fretting-induced damage of thin passive $\mathrm{TiO}_{2}$ film and the release of metal ions into the adjacent tissues occurred. The most potential harmful effects are caused with $\mathrm{V}$ and $\mathrm{Al}$ [37]. In [12, 13], the pulsed e-beam alloying of Ti-6Al-4V with zirconium was used to reduce the $\mathrm{V}$ and $\mathrm{Al}$ content in the surface layers. Zirconium was chosen because of its biocompatibility [37], also its adding increases the corrosion resistance and strength of Ti. Moreover, $\mathrm{Zr}$ is fully dissolved in both $\alpha$ - and $\beta$-Ti, what simplifies a formation of the Ti-Zr surface alloys by pulsed melting.

The multilayer film/substrate system $[\operatorname{Zr}(20 \mathrm{~nm}) / \operatorname{Ti}(20$ $\mathrm{nm})]_{12} /(\mathrm{Ti}-6 \mathrm{Al}-4 \mathrm{~V})$ with total thickness of $\mathrm{Zr} / \mathrm{Ti}$ coating of $480 \mathrm{~nm}$ was used in experiments. Ti and $\mathrm{Zr}$ layers were alternately deposited onto Ti-6Al-4V substrates using magnetron sputtering from pure $\mathrm{Ti}$ and $\mathrm{Zr}$ cathodes. Prior to deposition, the substrates were multiply irradiated with a LEHCEBs $\left(2.5 \mu \mathrm{s}, \sim 3 \mathrm{~J} / \mathrm{cm}^{2}\right)$ to avoid a local delamination of the thin film because of surface cratering [11].

As-deposited samples were subjected to one-pulse melting with LEHCEBs $\left(2.5 \mu \mathrm{s}, 3.5 \mathrm{~J} / \mathrm{cm}^{2}\right)$. As follows from AES data (Figure 15), a homogeneous liquid-phase intermixing of all Ti/Zr films and diffusion of $\mathrm{Zr}$ into the substrate up to a depth of $\sim 1 \mu \mathrm{m}$ takes place. The $\sim 0.5-\mu \mathrm{m}$-thick nearsurface layer is free of $\mathrm{Al}$ and $\mathrm{V}$. According to XRD and AES analyses, it has a single-phase solid solution $\alpha$ - $\left(\mathrm{Ti}_{70} \mathrm{Zr}_{30}\right)$ structure. The following vacuum annealing $\left(500^{\circ} \mathrm{C}, 2 \mathrm{~h}\right)$ leads to increase of alloyed layer in a depth up to $\sim 1.2 \mu \mathrm{m}$ and its enrichment with $\mathrm{O}$ and $\mathrm{C}$ impurities. The $\mathrm{Zr}$ and $\mathrm{Ti}$ concentration profiles before and after annealing are the same, and the surface layer of thickness of $\sim 0.5 \mu \mathrm{m}$ is free of $\mathrm{Al}$ and $\mathrm{V}$. Atom force microscopy (AFM) surface analysis of $\mathrm{Ti}-\mathrm{Zr}$ alloy revealed its nanosized structure with an average grain size of 110 and $90 \mathrm{~nm}$ before and after the vacuum annealing, respectively (Figure 16). The decrease in the grain size during annealing can be related to the 


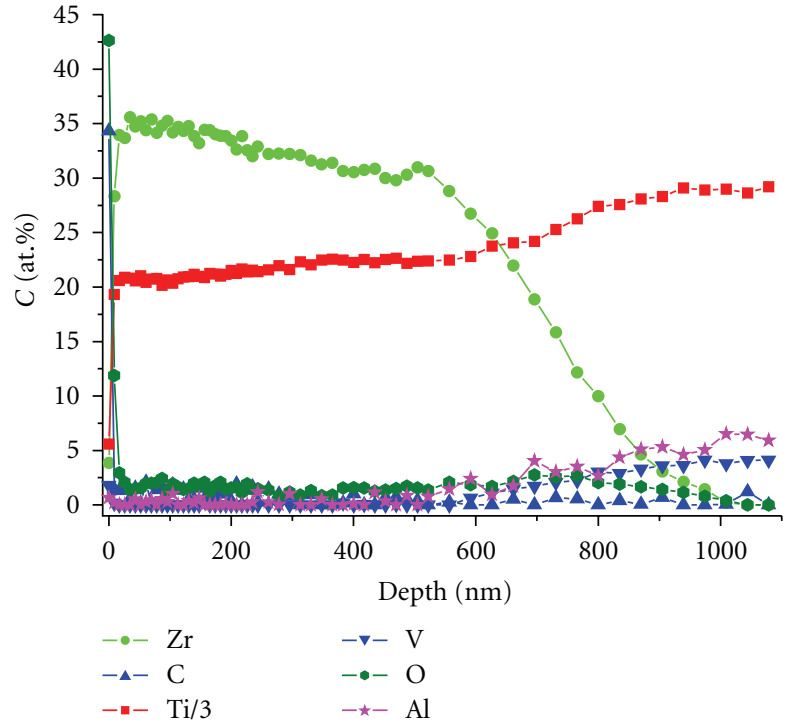

Figure 15: AES depth profiles of the elements in a $[\operatorname{Zr}(20 \mathrm{~nm}) /$ $\mathrm{Ti}(20 \mathrm{~nm})]_{12} /(\mathrm{Ti}-6 \mathrm{Al}-4 \mathrm{~V})$ system irradiated with $3.5 \mathrm{~J} / \mathrm{cm}^{2}, n=1$.

process of precrystallization recovery (initial stage of primary recrystallization) [38].

The nanoindentation depth profiles of substrate (Ti-6Al$4 \mathrm{~V}$ alloy) and the film-substrate system in dependence of treatment mode are shown in Figure 17. Preliminary multiple pulsed melting of substrate does not lead to its surface hardening (cf. curves 1 and 2). The deposition of a multilayer $\mathrm{Ti} / \mathrm{Zr}$ film and its subsequent single-pulse melting also does not modify the nanohardness profile (cf. curves 3 and 4). This can be related to the residual tensile stresses formed in the near-surface layers after irradiation. Subsequent vacuum annealing leads to a significant hardening of the surface alloy (curve 5). This can be explained by a decrease in residual tensile stresses and dispersion strengthening due to forming oxide and carbide precipitates.

Thus, this method allows forming on a Ti-6Al-4V substrate the single-phase $\alpha\left(\mathrm{Ti}_{70} \mathrm{Zr}_{30}\right)$ surface alloy, free of $\mathrm{Al}$ and $\mathrm{V}$ and having nanosized structure and increased hardness due to subsequent vacuum annealing. The structure must also possess increased corrosion resistance owing to the homogeneity and more uniform distribution of impurities at the subgrain boundaries. The increase in the thickness of alloyed layer can be achieved by alternating the cycles of film deposition and pulsed melting in a single vacuum chamber. The results obtained suggest that the given approach can be used for development of the surface finish technology of modern medical implants.

4.3. Synthesis and Characterization of Ti ${ }_{3} A l / T i A l-B a s e d$ Surface Alloys. Bulk Ti ${ }_{3} \mathrm{Al} / \mathrm{TiAl}$-based alloys have several advantages over conventional $\mathrm{Ti}$ alloys, such as higher elastic modulus, lower density, better mechanical properties at elevated temperatures, and higher oxidation resistance [39]. These properties of $\mathrm{Ti}-\mathrm{Al}$ intermetallics make them suitable for use as structural protective coatings. Several techniques

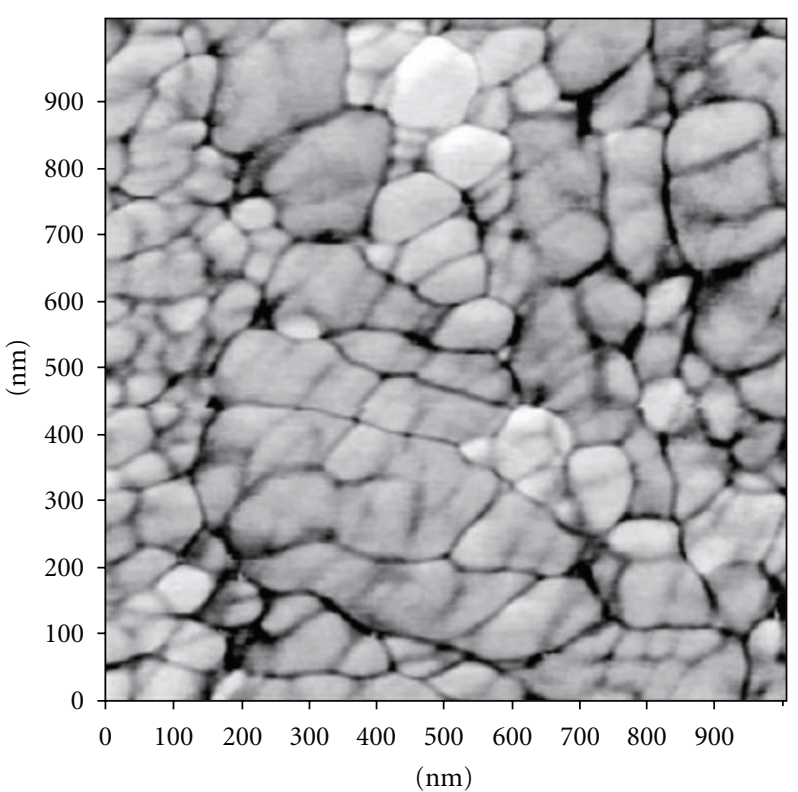

FIGURE 16: AFM image of surface of a $[\operatorname{Zr}(20 \mathrm{~nm}) / \operatorname{Ti}(20 \mathrm{~nm})]_{12} /$ (Ti-6Al-4V) system irradiated with $3.5 \mathrm{~J} / \mathrm{cm}^{2}, n=1$ followed by vacuum annealing.

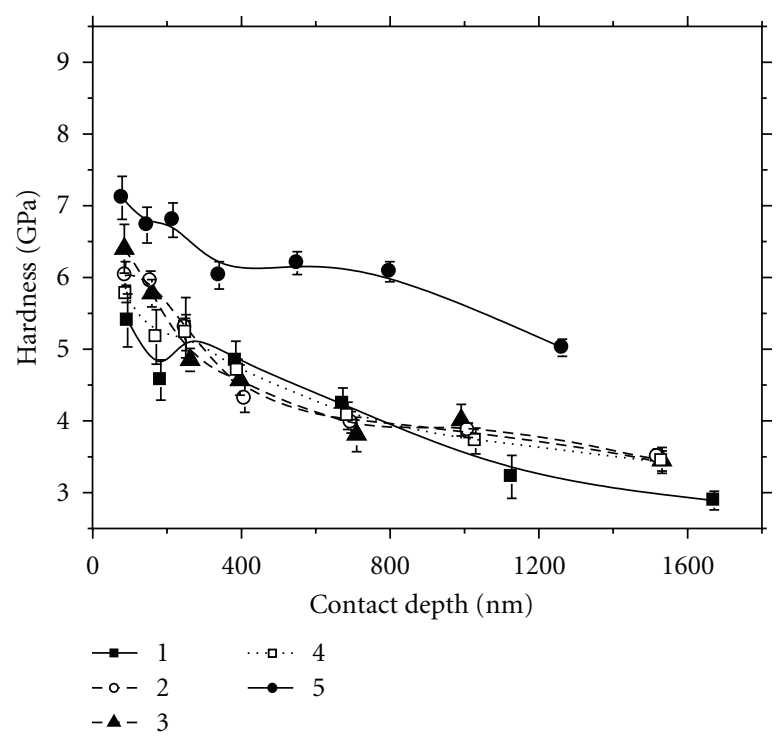

FIGURE 17: Nanohardness—depth profiles: $(1,2)$ substrate (Ti-6Al$4 \mathrm{~V}$ alloy) before and after multiple pulsed melting, respectively; $(3,4,5)[\mathrm{Zr}(20 \mathrm{~nm}) / \mathrm{Ti}(20 \mathrm{~nm})]_{12} /(\mathrm{Ti}-6 \mathrm{Al}-4 \mathrm{~V})$ system as-deposited, after pulsed melting $\left(3.5 \mathrm{~J} / \mathrm{cm}^{2}, n=1\right)$, and subsequent annealing, respectively.

to produce Ti-Al coatings have been developed in the last decade: thin-film deposition [40, 41], ion implantation [42], and laser melting deposition [43]. In [14, 15], the pulsed liquid-phase mixing of Ti substrate with predeposited Al film was firstly used to fabricate $\mathrm{Ti}_{3} \mathrm{Al} / \mathrm{TiAl}$-based surface alloys. The characterization of Ti-Al surface alloys depending on synthesis mode is also considered. 
Ti-Al surface alloys were formed in a single vacuum chamber by alternating the procedures of $\mathrm{Al}$ film deposition $\left(70 \div 100 \mathrm{~nm}\right.$ per cycle) and pulsed melting $\left(3.5 \mathrm{~J} / \mathrm{cm}^{2}, 3 \mu \mathrm{s}\right.$, $n=3 \div 5$ ). Pulsed high-current vacuum arc evaporator, described in [44], was used for film deposition. Prior to first deposition, the Ti substrates were irradiated with a LEHCEB $\left(2.5 \mu \mathrm{s}, \sim 5 \mathrm{~J} / \mathrm{cm}^{2}, n=10\right)$ to ensure high adhesion of the Al film. The maximum number of synthesis cycles $N$ was 40 , thus, the total thickness of deposited $\mathrm{Al}$ coating reached $\sim 4 \mu \mathrm{m}$.

According to energy dispersive X-ray (EDX) analysis, an increase in cycle number from 5 to 40 leads to an increase in the average $\mathrm{Al}$ content from $\sim 30$ up to $\sim 70$ at. $\%$ in the $\sim 3$ - $\mu \mathrm{m}$-thick surface layer. The $\sim 1-\mu \mathrm{m}$-thick surface layer was enriched with $8-10$ at.\% $\mathrm{Al}$ as compared to an average concentration. It agrees with $\mathrm{Ti}-\mathrm{Al}$ phase diagram [45], according to which $\mathrm{Al}$ during solidification will be pushed out from a growing crystal and will be accumulated at the surface.

$\mathrm{XRD}$ analysis has shown that increase in $\mathrm{Al}$ concentration in the surface layers is accompanied by the evolution of its phase composition (Figure 18). At $N=5$, the crackfree surface alloy Ti-31 at.\% Al consisting of $\sim 70$ vol. $\% \alpha$ $\mathrm{Ti}$ (balance is hexagonal $\mathrm{Ti}_{3} \mathrm{Al}$ ) is formed (Figure 18(a)). At $N=10$, the surface alloy Ti-43 at.\% $\mathrm{Al}$ based on $\mathrm{Ti}_{3} \mathrm{Al}(\sim 85 \mathrm{vol} . \%)$ is formed. The second phases are $\alpha$ $\mathrm{Ti}(\sim 13$ vol.\%) and TiAl- $(\gamma)$ (Figure 18(b)). In general, in the range of $N=10 \div 20$, the surface alloys Ti- (4363 at.\% $\mathrm{Al}$ ) of thickness $\geq 3 \mu \mathrm{m}$ based on $\mathrm{Ti}_{3} \mathrm{Al}$ and $\mathrm{TiAl}$ phases are formed (Figures 18(b), 18(c), and 18(d)); herein, content of TiAl increases from $\sim 2$ up to $\sim 74$ vol. $\%$. The evaluated lattice constants of $\gamma$ (TiAl)-phase, synthesized at $N=20$, are $a=0.4017$ and $=0.4023 \mathrm{~nm}$. It means that, in contrast to the equilibrium ordered tetragonal TiAl phase [39], the tetragonal distortion ratio (c/a) is close to 1 . This may be due to the deviation of the $\gamma$-phase formed from the stoichiometry and/or a relatively high level of residual stresses which remains even after vacuum annealing $\left(700^{\circ} \mathrm{C}\right.$, $1 \mathrm{~h})$. The average coherent scattering domain (CSD) size of $\gamma$-phase is $\sim 15 \mathrm{~nm}$. AFM analysis of TiAl-based surface alloy revealed its nanosized structure with an average grain size of $\sim 70 \mathrm{~nm}$ (Figure 19).

Cracking was found in all the surface alloys containing $\gamma$ phase. Cracking is associated with the formation of residual tensile stresses in the surface layers of the target irradiated with LEHCEBs, as well as with a low ductility of $\gamma$-phase at room temperature [39]. In an attempt to reduce residual stresses and to form a crack-free uniform microstructure, selected surface-alloyed samples $(N=40, \mathrm{Ti}-70$ at.\% $\mathrm{Al})$ were subjected to subsequent pulsed melting by LEHCEBs $\left(3 \mu \mathrm{s}, 3 \div 5 \mathrm{~J} / \mathrm{cm}^{2}\right)$ at $\sim 700^{\circ} \mathrm{C}$, as well as by submillisecond ebeam $\left(15 \mathrm{keV}, 100 \mu \mathrm{s}, 10 \div 15 \mathrm{~J} / \mathrm{cm}^{2}\right)$ at RT. It is expected that such treatment, due to increase in melt lifetime and partial evaporation, will lead to a decrease in the $\mathrm{Al}$ concentration and, hence, to decrease in content of a brittle $\gamma$-phase.

XRD patterns of the crack-free surface alloys are shown in Figures $18(\mathrm{~g})$ and $18(\mathrm{~h})$. In both modes, they have the composition of Ti-(34-35) at.\% $\mathrm{Al}$, and the matrix phase is $\mathrm{Ti}_{3} \mathrm{Al}$ (76 and 96 vol.\%, respectively), which agrees with the

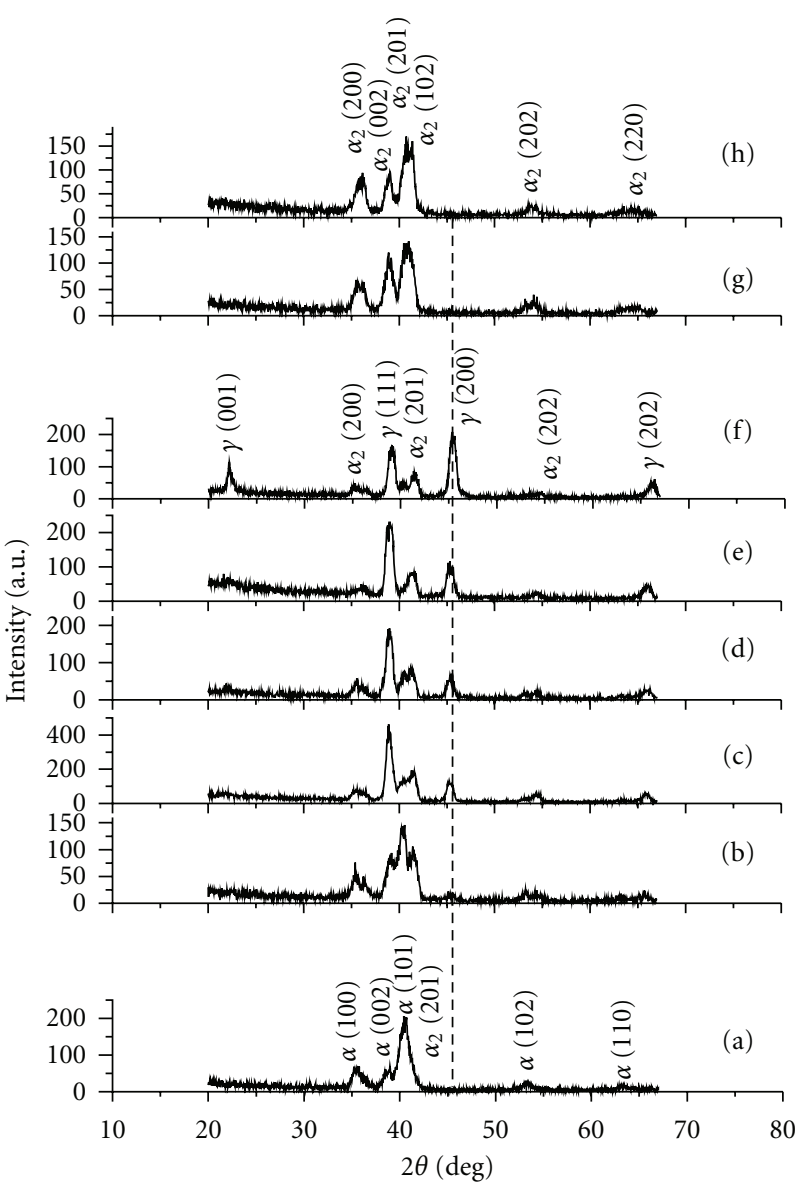

FIGURE 18: XRD patterns of the of the Ti-Al surface alloys formed in different modes: (a) $N=5$; (b) $N=10$; (c) $N=15$; (d) and (e) $N=15$ followed by vacuum annealing $\left(700^{\circ} \mathrm{C}, 1 \mathrm{~h}\right)$; (f) $N=20$; (g) $N=40$ followed by pulsed melting $\left(3 \mu \mathrm{s}, 4-5 \mathrm{~J} / \mathrm{cm}^{2}, n=3, T_{0}=\right.$ $\left.680^{\circ} \mathrm{C}\right)$; (h) $N=40$ followed by pulsed melting $\left(100 \mu \mathrm{s}, 13 \mathrm{~J} / \mathrm{cm}^{2}\right.$, $n=9$ ). XRD patterns (a) and (e) are obtained at incident angle $\omega=2^{\circ}$, others at $\omega=5^{\circ}$.

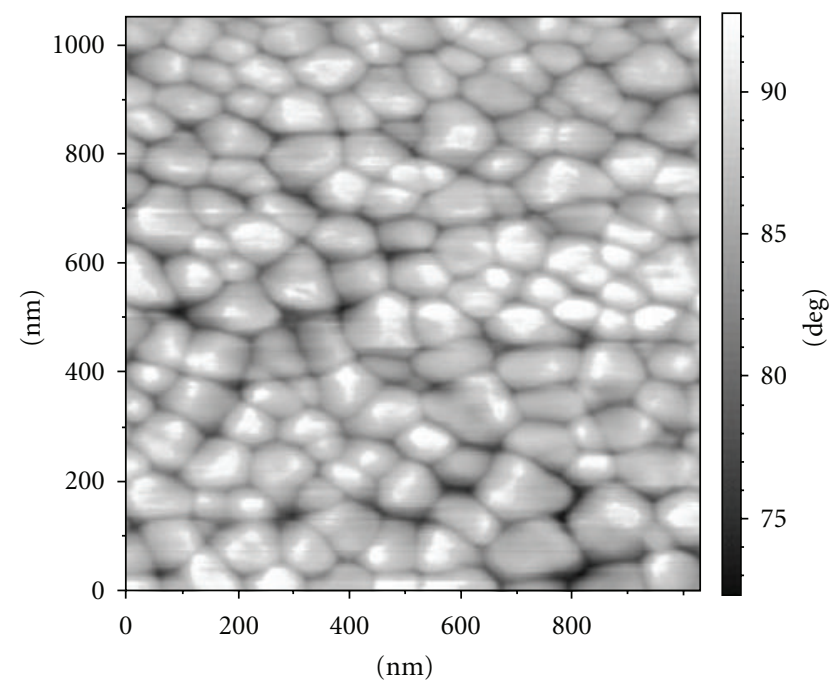

FIGURE 19: AFM surface image of the $\gamma$-(TiAl-)based surface alloy, synthesized at $N=20$. 


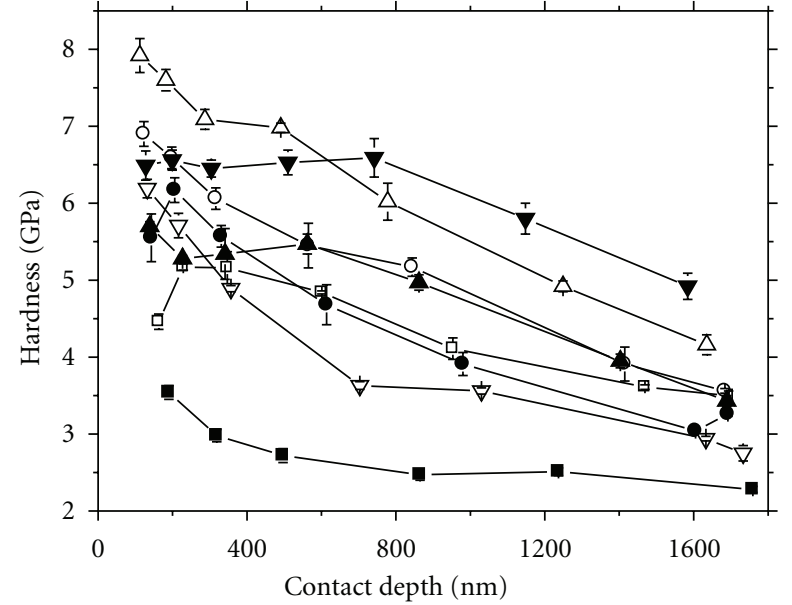

Figure 20: Nanohardness-depth profiles for Ti substrate $(\boldsymbol{\square})$ and Ti-Al surface alloys, fabricated at various processing conditions: $(\nabla)$ $N=5 ;(\bullet) N=10 ;(\square) N=15 ;(\bigcirc) N=15$ followed by vacuum annealing $\left(700^{\circ} \mathrm{C}, 1 \mathrm{~h}\right) ;(\boldsymbol{\Delta}) N=20 ;(\Delta) N=40$ followed by pulsed melting $\left(3 \mu \mathrm{s}, 4-5 \mathrm{~J} / \mathrm{cm}^{2}, n=3, \quad T_{0}=680^{\circ} \mathrm{C}\right) ;(\boldsymbol{\nabla}) N=40$ followed by pulsed melting $\left(100 \mu \mathrm{s}, 13 \mathrm{~J} / \mathrm{cm}^{2}, n=9\right)$.

Ti-Al phase diagram. Despite the lowered thermal stresses, the $\mathrm{Ti}_{3} \mathrm{Al}$ phase is characterized by high-lattice strain $\left(\sim 10^{-2}\right)$ and small CSD size $(15-20 \mathrm{~nm})$, as evidenced by the significant broadening of lines of this phase. According to the AFM analysis, the average grain size of $\mathrm{Ti}_{3} \mathrm{Al}$-based surface alloy, formed at $N=40$ followed by submillisecond melting is $\sim 250 \mathrm{~nm}$, that is, higher by factor of $\sim 3.5$ than that of TiAlbased surface alloy, synthesized at $N=20$. The increase in grain size is associated with a decrease in the rate of quench from the melt from $\sim 10^{9}$ to $\sim 10^{6} \mathrm{~K} / \mathrm{s}$.

Figure 20 shows the nanohardness depth profiles of Ti-Al surface alloys. A significant increase in hardness compared to that of Ti-substrate is observed. At $N=5 \div 15$, the thickness of hardening layers $\left(\alpha-\mathrm{Ti}^{2} / \mathrm{Ti}_{3} \mathrm{Al} / \mathrm{TiAl}\right)$ does not exceed 1.5-2 $\mu \mathrm{m}$. The monotonic decrease in hardness with depth is associated with the influence of soft Ti substrate. Comparison of the nanohardness profiles obtained at $N=$ 10,15 , and 20 , taking into account the XRD data, shows that the $\mathrm{TiAl}$ and $\mathrm{Ti}_{3} \mathrm{Al}$ phases give a comparable contribution to the increase in hardness. Postsynthesis $(N=15)$ vacuum annealing leads to an additional increase in hardness and to the smoothing of hardness profile. The first is associated with a reduction of the residual tensile stresses induced by pulsed melting; the second-with a more uniform depth distribution of $\mathrm{Al}$ in the depth due to liquid-phase diffusion.

The maximum increase in the hardness (by a factor of $\sim 2.5$ ) and the thickness of hardened layer (up to $\sim 2 \mu \mathrm{m}$ ) takes place in two crack-free modes, mentioned above when the $\mathrm{Ti}_{3} \mathrm{Al}$ - based surface alloys of average composition Ti33 at.\% $\mathrm{Al}$ were formed. The evaluated Young's modulus of the $\sim 1-\mu$ m-thick crack-free surface layers is $130 \div 150 \mathrm{GPa}$, which agrees with that of $\mathrm{Ti}_{3} \mathrm{Al}$ [39]. The hardness depth profile of the crack-free surface alloy, fabricated due to additional submillisecond melting, has the $\sim 1 \mu \mathrm{m}$ thick plateau. This is an evidence of more uniform microstructure in depth compared to as-synthesized surface alloy. The thickness correlates with the evaluated diffusion length of $\mathrm{Al}$ atoms into the liquid $\mathrm{Ti}$.

Thus, using multiple procedures of $\mathrm{Al}$ film deposition onto Ti substrate followed by pulsed melting, the TiAl surface alloys in the wide range of composition have been formed under systematically varied conditions. The $\mathrm{TiAl} / \mathrm{Ti}_{3} \mathrm{Al}$-based surface alloys with nanosized and ultrafine grain structure have been synthesized successfully. The thickness of these alloys ( $\geq 3 \mu \mathrm{m}$ ) is about one order of magnitude higher than that achieved by the high-dose ion implantation. In order to increase the ductility and suppress the surface cracking of TiAl-based surface alloys, the microalloying (e.g., $\mathrm{Nb}, \mathrm{Cr}$ ) can be used by analogy with bulk materials [39].

\section{Conclusions}

The results obtained have demonstrated that pulsed melting of $\mathrm{Al}$ and $\mathrm{Ti}$ alloys with microsecond LEHCEBs is a promising technique for enhancement of surface-sensitive properties of these alloys. The main findings are as follows.

(1) The multiple pulsed melting of Al6061 alloy enhances the corrosion resistance due to complete dissolving of second-phase particles and formation of a uniform oxide film. The irradiation of Al2024 and Al6061 alloys allows one to increase wear resistance due to the strain hardening induced by pulsed heating.

(2) In case of Ti-6Al-4V alloy, multiple pulsed melting leads to increase in corrosion resistance at initial temperature of the target up to $550^{\circ} \mathrm{C}$ due to homogenization of the surface layer. Significant increase in wear resistance compared to the untreated $\mathrm{Ti}$ alloy has been recorded after irradiation at $550^{\circ} \mathrm{C}$, as well as after irradiation at RT followed by vacuum annealing. This agrees with the increase in the surface microhardness and correlates with stress relief and saturation of near-surface layer with oxygen.

(3) Liquid-phase mixing of the multilayer $\mathrm{Ti} / \mathrm{Zr}$ thin films predeposited onto a Ti-6Al-4V substrate allows forming the single-phase nanocrystalline $\alpha(\mathrm{TiZr})$ surface alloy, free of $\mathrm{Al}$ and $\mathrm{V}$. Subsequent vacuum annealing leads to increase in nanohardness of the surface alloy. The structure must possess enhanced corrosion resistance owing to uniform distribution of impurities.

(4) Multiple procedures of $\mathrm{Al}$ film deposition onto Ti substrate followed by pulsed melting allow to form nanosized and ultrafine grain $\mathrm{TiAl} / \mathrm{Ti}_{3} \mathrm{Al}$-based surface alloys of thickness $\geq 3 \mu \mathrm{m}$. The main problem is cracking of TiAl-based surface alloys.

\section{References}

[1] D. I. Proskurovsky, V. P. Rotshtein, and G. E. Ozur, "Use of low-energy, high-current electron beams for surface treatment of materials," Surface and Coatings Technology, vol. 96, no. 1, pp. 117-122, 1997. 
[2] D. I. Proskurovsky, V. P. Rotshtein, G. E. Ozur et al., "Pulsed electron-beam technology for surface modification of metallic materials," Journal of Vacuum Science and Technology, vol. 16, no. 4, pp. 2480-2488, 1998.

[3] G. E. Ozur, D. I. Proskurovsky, V. P. Rotshtein, and A. B. Markov, "Production and application of low-energy highcurrent electron beams," Laser and Particle Beams, vol. 21, no. 2, pp. 157-174, 2003.

[4] A. B. Markov and V. P. Rotshtein, "Calculation and experimental determination of dimensions of hardening and tempering zones in quenched U7A steel irradiated with a pulsed electron beam," Nuclear Instruments and Methods in Physics Research, Section, vol. 132, no. 1, pp. 79-86, 1997.

[5] V. P. Rotshtein, A. B. Markov, and Y. F. Ivanov, "Surface treatment of materials with low-energy, high-current electron beam," in Materials Surface Processing by Directed Energy Techniques, Y. Pauleau, Ed., chapter 6, pp. 205-240, Elsevier, Amsterdam, The Netherlands, 2006.

[6] D. I. Proskurovsky, V. P. Rotshtein, G. E. Ozur, Y. F. Ivanov, and A. B. Markov, "Physical foundations for surface treatment of materials with low energy, high current electron beams," Surface and Coatings Technology, vol. 125, no. 1-3, pp. 49-56, 2000.

[7] Y. Ivanov, W. Matz, V. Rotshtein, R. Gunzel, and N. Shevchenko, "Pulsed electron-beam melting of high-speed steel: structural phase transformations and wear resistance," Surface and Coatings Technology, vol. 150, no. 2-3, pp. 188-198, 2002.

[8] D. S. Nazarov, A. B. Markov, G. E. Ozur et al., "Modification of the structure and properties of aluminium alloys by low energy high current electron beams," in Proceedings of the 5th International Conference on Electron Beam Technologies, pp. 209-214, Varna, Bulgaria, June 1997.

[9] I. M. Goncharenko, V. I. Itin, S. V. Isichenko et al., "Increasing of corrosion resistance of the $12 \mathrm{X} 18 \mathrm{H} 10 \mathrm{~T}$ steel irradiated by low-energy high-current electron beam," Protection of Metals, vol. 29, no. 6, pp. 932-937, 1993.

[10] V. P. Rotshtein, D. I. Proskurovsky, G. E. Ozur, Y. F. Ivanov, and A. B. Markov, "Surface modification and alloying of metallic materials with low-energy high-current electron beams," Surface and Coatings Technology, vol. 180-181, pp. 377-381, 2004.

[11] V. P. Rotshtein, Y. F. Ivanov, A. B. Markov et al., "Surface alloying of stainless steel 316 with copper using pulsed electron-beam melting of film-substrate system," Surface and Coatings Technology, vol. 200, no. 22-23, pp. 6378-6383, 2006.

[12] A. V. Batrakov, A. B. Markov, G. E. Ozur, D. I. Proskurovsky, and V. P. Rotshtein, "Surface alloying of metallic substrates with pre-deposited films through a pulsed electron-beam mixing," The European Physical Journal, vol. 43, no. 3, pp. 283288, 2008.

[13] V. P. Rotshtein, A. B. Markov, N. Shevchenko, H. Reuther, K. V. Oskomov, and V. A. Shulov, "Surface doping of VT6 alloy with zirconium by pulsed electron-beam mixing of predeposited multilayer Zr/Ti film," Technical Physics Letters, vol. 34, no. 10, pp. 891-894, 2008.

[14] V. P. Rotshtein, Y. F. Ivanov, Y. A. Kolubaeva et al., "Synthesis of $\mathrm{Ti}_{3} \mathrm{Al} / \mathrm{TiAl}$ based surface alloys by pulsed electron-beam melting of Al/Ti film-substrate system," in Proceedings of the 10th International Conference on Modification of Materials with Particle Beams and Plasma Flows, pp. 416-419, Tomsk, Russia, 2010.

[15] V. P. Rotshtein, Y. F. Ivanov, Y. A. Kolubaeva et al., "Synthesis of $\mathrm{Ti}_{3} \mathrm{Al}$ and $\mathrm{TiAl}$ based surface alloys by pulsed electron-beam melting of $\mathrm{Al}$ (film)/Ti (substrate) system," Technical Physics Letters, vol. 37, no. 3, pp. 226-229, 2011.

[16] S. F. Gnyusov, S. Y. Tarasov, Y. F. Ivanov, and V. P. Rothstein, "The effect of pulsed electron beam melting on microstructure,friction and wear of WC-Hadfield steel hard metal," Wear, vol. 257, no. 1-2, pp. 97-103, 2004.

[17] K. M. Zhang, D. Z. Yang, J. X. Zou, T. Grosdidier, and C. Dong, "Improved in vitro corrosion resistance of a NiTi alloy by high current pulsed electron beam treatment," Surface and Coatings Technology, vol. 201, no. 6, pp. 3096-3102, 2006.

[18] J. X. Zou, T. Grosdidier, K. M. Zhang, and C. Dong, "Crosssectional analysis of the graded microstructure in an AISI D2-steel treated with low energy high-current pulsed electron beam," Applied Surface Science, vol. 255, no. 9, pp. 4758-4764, 2009.

[19] T. Grosdidier, J. X. Zou, B. Bolle, S. Z. Hao, and C. Dong, "Grain refinement, hardening and metastable phase formation by high current pulsed electron beam (HCPEB) treatment under heating and melting modes," Journal of Alloys and Compounds, vol. 504, supplement 1, pp. S508-S511, 2010.

[20] J. X. Zou, K. M. Zhang, S. Z. Hao, C. Dong, and T. Grosdidier, "Mechanisms of hardening, wear and corrosion improvement of 316 L stainless steel by low energy high current pulsed electron beam surface treatment," Thin Solid Films, vol. 519, no. 4, pp. 1404-1415, 2010.

[21] E. Dudarev, G. Pochivalova, D. Proskurovsk, V. Rotshtein, and A. Markov, "Microplastic deformation of polycrystalline iron and molybdenum subjected to high-current electron-beam irradiation," Russian Physics Journal, vol. 39, no. 3, pp. 284$288,1996$.

[22] W. Mullins and R. Secerka, "Stability of a planar interface during solidification of a dilute binary alloy," Journal of Applied Physics, vol. 35, pp. 444-451, 1964.

[23] A. Cullis, D. Hurle, H. Webber et al., "Growth interface breakdown during laser recrystallization from the melt," Applied Physics Letters, vol. 38, no. 8, pp. 642-644, 1981.

[24] N. A. Nochovnaya, V. A. Shulov, V. P. Rotshtein et al., "Modification of the structure and properties of titanium alloys by low-energy, high-current electron beams," in Proceedings of the 5th International Conference on Electron Beam Technologies, pp. 215-220, Varna, Bulgaria, June 1997.

[25] N. A. Nochovnaya, V. A. Shulov, D. S. Nazarov et al., "Treatment of parts made of titanium alloys with low-energy, high-current electron beams of microsecond duration," Fizika i Khimiya Obrabotki Materialov, vol. 1, pp. 27-33, 1998.

[26] K. Uemura, S. Uehara, P. Raharjo, D. I. Proskurovsky, G. E. Ozur, and V. P. Rotshtein, "Surface modification process on metal dentures, products produced thereby, and the incorporated system thereof," US Patent, US 6863531 B2, 2006.

[27] V. P. Rotshtein, Y. F. Ivanov, D. I. Proskurovsky, K. V. Karlik, I. A. Shulepov, and A. B. Markov, "Microstructure of the nearsurface layers of austenitic stainless steels irradiated with a low-energy, high-current electron beam," Surface and Coatings Technology, vol. 180-181, pp. 382-386, 2004.

[28] V. P. Rotshtein, R. Gunzel, A. B. Markov et al., "Surface modification of titanium alloy with a low-energy high-current electron beam at elevated initial temperatures," Fizika i Himiya Obrabotki Materialov, vol. 1, pp. 62-72, 2006 (Russian).

[29] C. Leyens and M. Peters, Titanium and Titanium Alloys: Fundamentals and Applications, Wiley-VCH, Weinheim, Germany, 2003. 
[30] N. D. Tomashov, "The development of the structural electrochemical theory of the corrosion of metals and alloys," Protection of Metals, vol. 22, no. 6, pp. 679-691, 1986.

[31] J. Poate, G. Remini, and D. Jacobson, Surface Modification and Alloying by Laser, Ion, and Electron Beams, Plenum Press, New York, NY, USA, 1983.

[32] C. Blanco-Pinzon, Z. Liu, K. Voisey et al., "Excimer laser surface alloying of titanium with nickel and palladium for increased corrosion resistance," Corrosion Science, vol. 47, no. 5, pp. 1251-1269, 2005.

[33] E. D'Anna, G. Leggieri, and A. Luches, “Thin film processing with pulsed electron beams," Thin Solid Films, vol. 182, no. 12, pp. 215-228, 1989.

[34] T. J. Renk, R. G. Buchheit, N. R. Sorensen, and D. Cowell, "Improvement of surface properties by modification and alloying with high-power ion beams," Physics of Plasmas, vol. 5, no. 5, pp. 2144-2150, 1998.

[35] Z. Werner, J. Piekoszewski, W. Szymczyk et al., "Palladium profiles in titanium treated by high-intensity plasma pulses," Surface and Coatings Technology, vol. 158-159, pp. 21-27, 2002.

[36] E. Richter, J. Piekoszewski, E. Wieser et al., "Modification of titanium surface by its alloying with silicon using intense pulsed plasma beams," Surface and Coatings Technology, vol. 158-159, pp. 324-327, 2002.

[37] S. G. Steineman, "Corrosion of surgical implants - in vivo and in vitro tests," in Evaluation of Biomaterials, G. D. Winter, J. L. Leroy, and K. de Goot, Eds., pp. 1-34, John Wiley \& Sons, Chichester, England, 1980.

[38] S. S. Gorelik, Recrystallization of Metals and Alloys, Metallurgy, Mir Publishers, Moscow, Russia, 2nd edition, 1978.

[39] F. H. Froes, C. Suryanarayana, and D. Eliezer, "Synthesis, properties and applications of titanium aluminides," Journal of Materials Science, vol. 27, no. 19, pp. 5113-5140, 1992.

[40] C. Leyens, M. Peters, and W. A. Kaysser, "Intermetallic Ti$\mathrm{Al}$ coatings for protection of titanium alloys: oxidation and mechanical behavior," Surface and Coatings Technology, vol. 94-95, pp. 34-40, 1997.

[41] J. Hampshire, P. J. Kelly, and D. G. Teer, "Structure and mechanical properties of co-deposited TiAl thin films," Thin Solid Films, vol. 420-421, pp. 386-391, 2002.

[42] I. Tsyganov, E. Wieser, W. Matz et al., "Phase formation in aluminum implanted titanium and the correlated modification of mechanical and corrosive properties," Thin Solid Films, vol. 376, no. 1-2, pp. 188-197, 2000.

[43] H. P. Qu and H. M. Wang, "Microstructure and mechanical properties of laser melting deposited $\gamma$-TiAl intermetallic alloys," Materials Science and Engineering, vol. 466, no. 1-2, pp. 187-194, 2007.

[44] S. A. Popov, D. I. Proskurovsky, E. L. Pryadko et al., "Highcurrent pulsed vacuum-arc evaporator for surface-alloying technologies," IEEE Transactions on Plasma Science, vol. 37, no. 8, pp. 1504-1510, 2009.

[45] J. L. Murray, Phase Diagrams of Binary Titanium Alloys, ASM International, Metals Park, Ohio, USA, 2nd edition, 1987. 

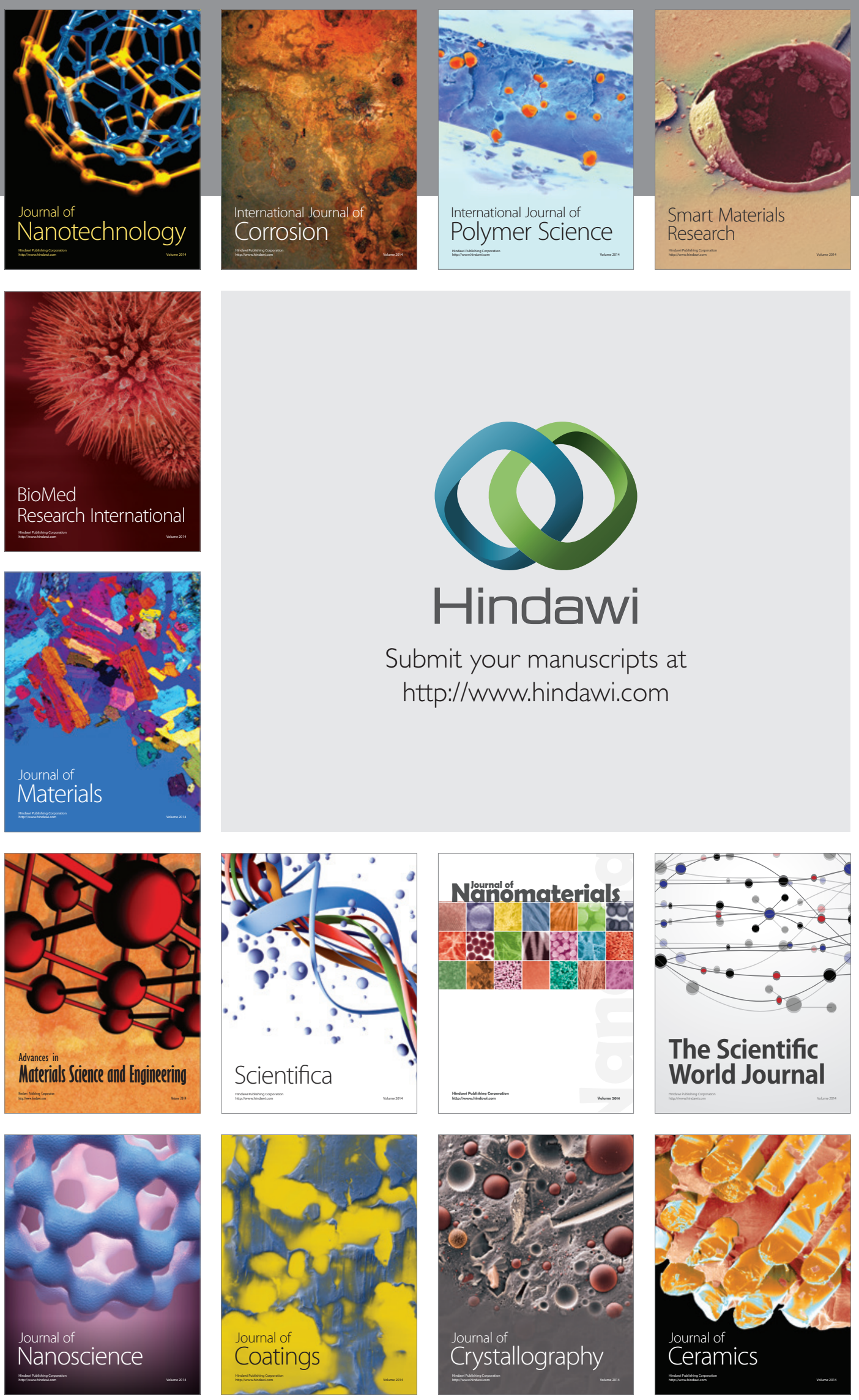

The Scientific World Journal

Submit your manuscripts at

http://www.hindawi.com

\section{World Journal}

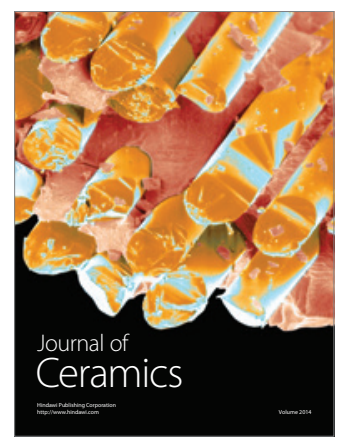

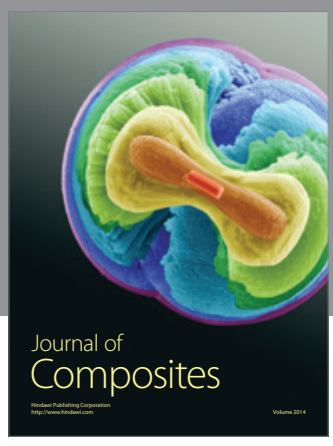
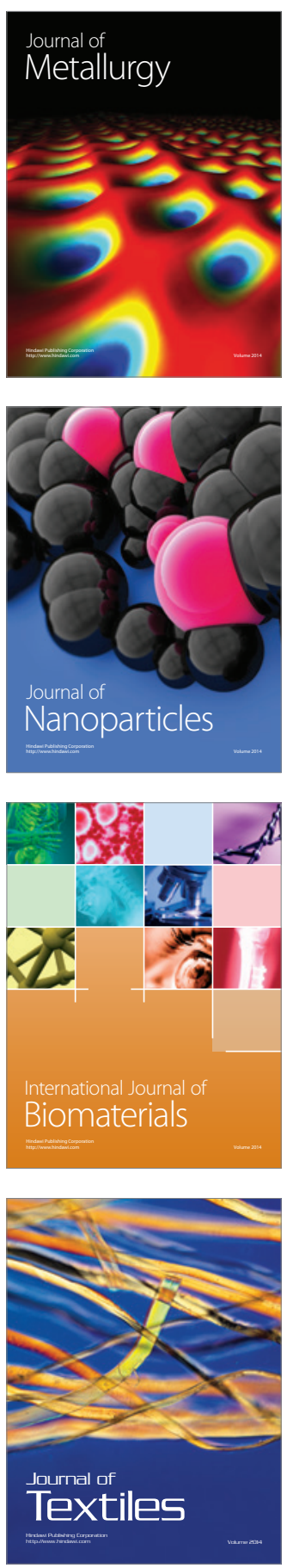